\title{
Examination of Hybrid Metal Coatings for Mitigation of Fission Product Release and Corrosion Protection of LWR SiC/SiC
}

Approved for public release. Distribution is unlimited.
Caen K. Ang Kurt Terrani Joseph Burns Yutai Katoh

September 12, 2016 


\section{DOCUMENT AVAILABILITY}

Reports produced after January 1, 1996, are generally available free via US Department of Energy (DOE) SciTech Connect.

Website http://www.osti.gov/scitech/

Reports produced before January 1, 1996, may be purchased by members of the public from the following source:

National Technical Information Service
5285 Port Royal Road
Springfield, VA 22161
Telephone 703-605-6000 (1-800-553-6847)
TDD 703-487-4639
Fax 703-605-6900
E-mail info@ntis.gov
Website http://www.ntis.gov/help/ordermethods.aspx

Reports are available to DOE employees, DOE contractors, Energy Technology Data Exchange representatives, and International Nuclear Information System representatives from the following source:

Office of Scientific and Technical Information

PO Box 62

Oak Ridge, TN 37831

Telephone 865-576-8401

Fax 865-576-5728

E-mail reports@osti.gov

Website http://www.osti.gov/contact.html

This report was prepared as an account of work sponsored by an agency of the United States Government. Neither the United States Government nor any agency thereof, nor any of their employees, makes any warranty, express or implied, or assumes any legal liability or responsibility for the accuracy, completeness, or usefulness of any information, apparatus, product, or process disclosed, or represents that its use would not infringe privately owned rights. Reference herein to any specific commercial product, process, or service by trade name, trademark, manufacturer, or otherwise, does not necessarily constitute or imply its endorsement, recommendation, or favoring by the United States Government or any agency thereof. The views and opinions of authors expressed herein do not necessarily state or reflect those of the United States Government or any agency thereof. 
Fuel Cycle Research and Development

\title{
Examination of Hybrid Metal Coatings for Mitigation of Fission Product Release and Corrosion Protection of LWR SiC/SiC
}

\author{
Caen Ang, Joseph Burns, Kurt Terrani, Yutai Katoh
}

Date Published: September $12^{\text {th }}, 201$

\author{
Prepared by \\ OAK RIDGE NATIONAL LABORATORY \\ Oak Ridge, TN 37831-6283 \\ managed by \\ UT-BATTELLE, LLC \\ for the \\ US DEPARTMENT OF ENERGY \\ under contract DE-AC05-00OR22725
}


This page is intentionally left blank 


\section{CONTENTS}

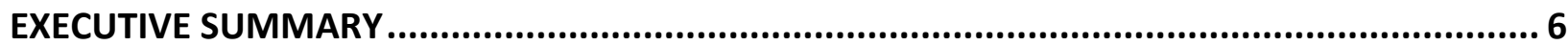

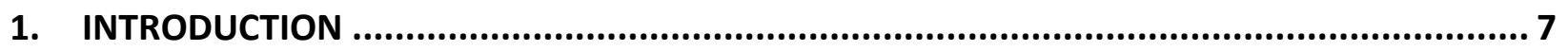

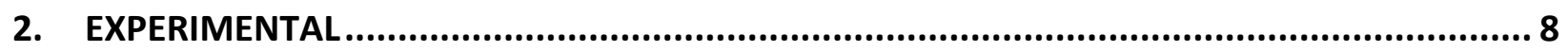

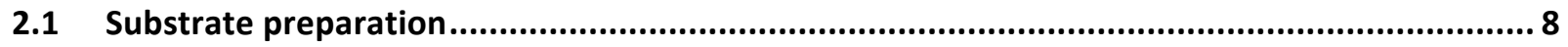

2.2 Electrolytic chromium or "hard chrome" ............................................................................ 9

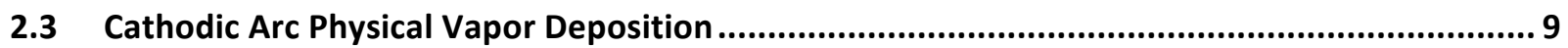

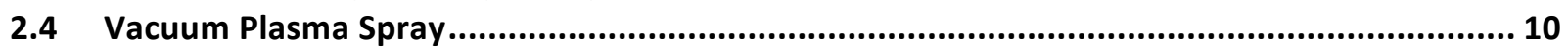

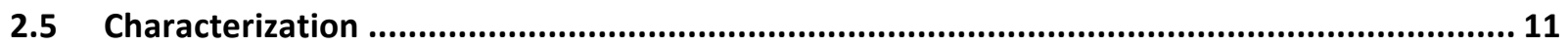

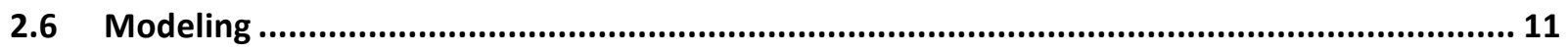

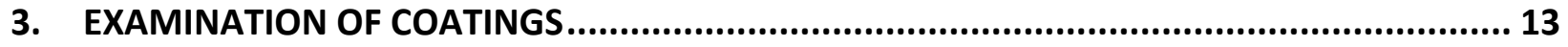

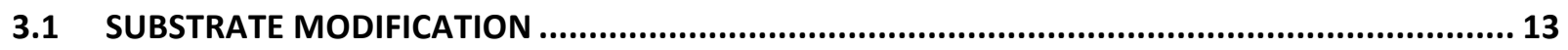

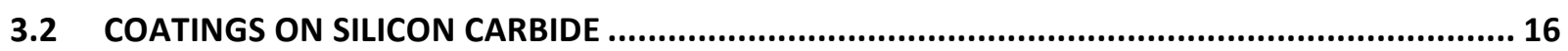

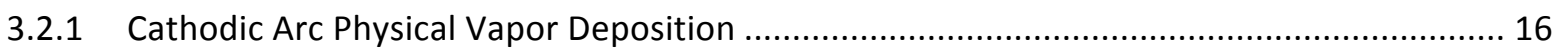

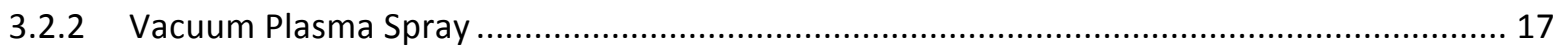

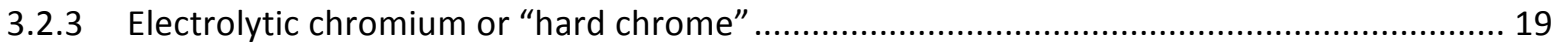

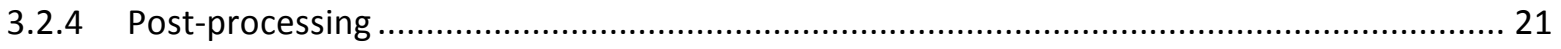

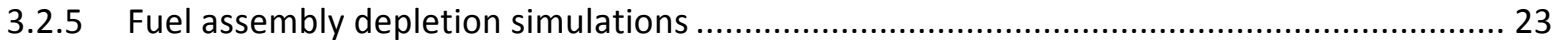

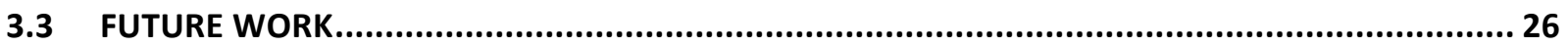

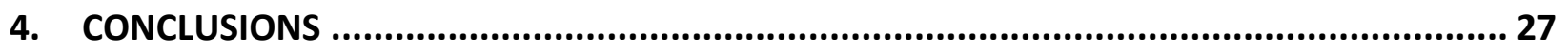

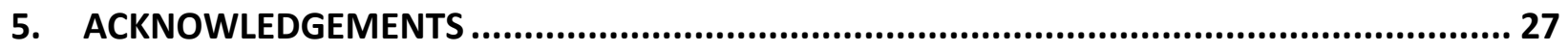

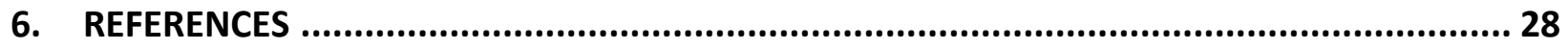




\section{EXECUTIVE SUMMARY}

There is a need to increase the safety margins of current and future light water reactors (LWRs) due to the unfortunate events at Fukushima Daiichi Nuclear Plant. Safety is crucial to restore public confidence in nuclear energy, acknowledged as an economical, high-density energy solution to climate change.

The development of accident-tolerant fuel (ATF) concepts is crucial to this endeavor. The objective of ATF is to delay the consequences of accident progression, being inset in high temperature steam and maintaining high thermomechanical strength for radionuclide retention. The use of advanced $\mathrm{SiC}_{\mathrm{f}}-\mathrm{SiC}$ composite as a substitute for zircaloy-based cladding is being considered. However, at normal operations, SiC is vulnerable to the reactor coolant and may corrode at an unacceptable rate. As a ceramic-matrix composite material, it is likely to undergo microcracking operation, which may compromise the ability to contain gaseous fission products.

A proposed solution to both issues is the application of mitigation coatings for use in normal operations. At Oak Ridge National Laboratory (ORNL), three coating technologies have been investigated with industry collaborators and vendors. These are electrochemical deposition, cathodic arc physical vapor deposition (PVD hereafter) and vacuum plasma spray (VPS). The objective of this document is to summarize these processing technologies, the resultant as-processed microstructures and properties of the coatings.

In all processes, substrate constraint resulted in substantial tensile stresses within the coating layer. Each technology must mitigate this tensile stress. Electrochemical coatings use chromium as the coolant facing material, and are deposited on a nickel or carbon "bond coat". This is economical but suffers microcracking in the chromium layer. PVD-based coatings use chromium and titanium in both metallic form and nitrides, and can be deposited defense-in-depth as multilayers. This vapor method eliminated tensile stress during processing and coatings were up to $\sim 30 \mu \mathrm{m}$ thick without microcracking. VPS produced coatings based on Zircaloy-2, which has a proven reactor-compatibility. The tensile stresses appearred to be partially mitigated by annealing. Analysis showed that VPS coatings required further optimizations to prevent adverse reactions with the substrate and need a minimum thickness of $\sim 50 \mu \mathrm{m}$. In addition, development of coatings are constrained by neutronic depletion analysis, which clearly indicated enrichment as an issue if the coating is too thick.

Based on the present work, the cathodic arc PVD technology was considered ready for the extensive testing and evaluation on cladding materials due to their ability to mitigate the excessive tensile stresses and the reasonable coating quality achieved. The VPS Zircaloy-2 coating technology required additional development toward mitigation of issues related to the substrate reaction and porosity. In the future, PVD and VPS will have be scaled upon successful development and demonstration. Electrochemical coatings, which are proven scalability, currently require development to mitigate issues related to the tensile stress after deposition. 


\section{INTRODUCTION}

$\mathrm{SiC}_{\mathrm{f}}$-SiC composites are continuing to undergo evaluation under the Advanced Fuels Campaign for light water reactors (LWRs) as an accident tolerant fuel (ATF) cladding.[1, 2] However, under operational conditions, the poor hermeticity due to stress-induced microcracking and corrosion rate of SiC cladding are expected to be unacceptable.[3] Details of the corrosion rate in LWR coolant can be found here.[3-7] Differential stressinduced microcracking and hermeticity has been documented on prototype cladding sections.[8-10] Together, both hermeticity and corrosion are a serious feasibility issue. A metallic coating is a possible solution to both issues.

The cladding is currently manufactured via a chemical vapor infiltration (CVI) route; this identical to the process used as the coating layer in microencapsulated fuel forms[11], and its behavior under irradiation is well-documented[12]. The fibers are woven or braided into a preformed tube. The CVI matrix is applied, followed by chemical vapor deposition (CVD) process to form a dense SiC layer on the cladding surface.

The addition of a coating as the final step in CVD may be problematic due to the inability to prevent interface reactions from occurring. Deposition technologies are being investigated as a solution to both problems based on successful $\mathrm{Zr}$ and $\mathrm{Cr}$ metals that are compatible in LWR coolant.[13, 14] A list of candidates is shown below in Table I, showing the status and the challenges remaining.

Table I. Candidate SiC-coating systems based on coolant facing material and deposition technology.

\begin{tabular}{|l|l|l|l|}
\hline Coating & Technology & Status & Current challenge \\
\hline $\mathrm{C}-\mathrm{Cr}$ & Electrochemical & Development & Alloying required to mitigate microcracks \\
\hline $\mathrm{Ni}-\mathrm{Cr}$ & Electrochemical & Development & As above, interface modification needed \\
\hline $\mathrm{Cr}$ & PVD & Evaluating & Unknown behavior with SiC interface \\
\hline $\mathrm{CrN}_{(1-\mathrm{x})}$ & PVD & Evaluating & As above, unknown irradiation behavior \\
\hline $\mathrm{TiN}_{(1-\mathrm{x})}$ & PVD & Evaluating & As above, unknown irradiation behavior \\
\hline $\mathrm{CrN} / \mathrm{Cr}$ & PVD & Evaluating & As above, unknown irradiation behavior \\
\hline $\mathrm{Zr}$ & VPS & Development & Interface reaction during processing \\
\hline $\mathrm{Cr}$ & VPS & Development & Not examined \\
\hline
\end{tabular}

Since these are corrosion resistant metals, which are constantly under an anodic potential, a process must be established to prevent oxidation during processing. Electrochemical deposition, cathodic arc physical vapor deposition (PVD) and vacuum plasma spray (VPS) can all mitigate chemical oxidation and this hurdle can be considered solved. The process control itself is non-trivial; the coating and SiC substrate must maintain an interface irrespective of stresses. This is the very definition of a coating. Such stresses include coefficient of thermal expansion (CTE) during deposition, densification of the coating and stresses caused by lowtemperature irradiation during reactor operation.

This report documents the processing of coatings on $\mathrm{SiC}$ and examines their potential feasibility. This report was initiated under the Advanced Fuels Campaign of the Fuel Cycle R\&D program, Office of Nuclear Energy, US Department of Energy. Section 2 reports the necessary preparations required to deposit coatings, the three chosen deposition technologies and equipment used. Section 3 details the types of stresses found in the coatings, discusses the effect of surface preparation and shows the morphology of the deposition methods. Section 4 explains the coating strategy, offers some perspectives, reports the status and development, and concludes with the future directions being undertaken to ensure success of the program. 


\section{EXPERIMENTAL}

\subsection{SUBSTRATE PREPARATION}

The part to be coated is referred to as the substrate from here onward. The substrate was high purity, stoichiometric CVD SiC from Dow Chemical Company, PA or Hi-Nicalon Type S SiC $\mathrm{f}_{\mathrm{f}} \mathrm{SiC}$. Substrate preparation was typical of electroless methods, including metallization.[15-18] SiC was cleaned with acetone, alkali and nitric acid, followed by etching. Etchants included $\mathrm{HF}, \mathrm{HSO}_{3} \mathrm{~F}, \mathrm{Na}_{2} \mathrm{CO}_{3}$ and $\mathrm{NaOH}$. This was critical in providing adhesion for the coating, because the surface roughness of CVD SiC is inadequate.

Some materials were sent to industrial vendors after etching to be coated. However, others required a bond coat (also called compatibility coating), which was deposited at Oak Ridge National Laboratory (ORNL) by an electroless process. The electroless process deposited a thin layer of nickel to support the cathodic reduction processes required for other methods. For example, it ensures $\mathrm{SiC}$ is electrically conductive to the $\mathrm{Cr}$ ions approaching the substrate, or provides a weak interface for crack deflection.

When conducted correctly, the electroless process deposits homogeneously on any material, and is insensitive to geometry. It is often used to prepare non-metallics of unusual shapes, in preparation for another coating. A schematic is shown below in Figure 1.

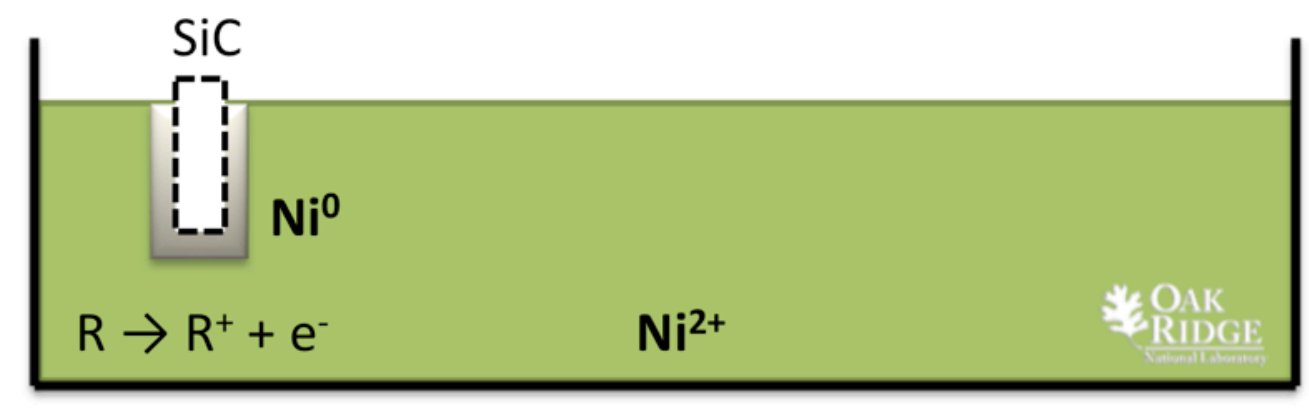

Figure 1. Schematic of the electroless deposition process of Ni plating. The reductant (R) supplies electrons which reduce the metal ions on the substrate.

Metals such as $\mathrm{Cr}$ and $\mathrm{Zr}$ are not easily stabilized in aqueous solution. The metal with the lowest coefficient of thermal expansion (CTE) that can be stabilized for electroless deposition is nickel (Ni). In the electroless $\mathrm{Ni}$ process, $\mathrm{Ni}^{2+}$ is in solution and reacting with the reductant $(\mathrm{R})$, and the bath is homogenously, slowly reducing metallic ions. A bath left in this state deposits ground-state Ni atoms over a period of weeks or months. However, it is accelerated on the substrate due to surface preparation. The plating rate was adjusted by the composition of plating bath, $\mathrm{pH}$ and deposition temperature. The electroless plating of nickel occurred above $70^{\circ} \mathrm{C}$. The plating bath was a C-MAG HS4 controlled system, with a PT1000-60 feedback temperature probe (IKA, Wilmington, NC) using a proprietary glass coating.

A second compatibility coat was pyrolytic carbon (PyC), which added surface electrical conductivity to SiC. This investigated the feasibility of a graded interface of SiC-PyC, using CVD SiC overcoated with PyC. When the CVI matrix is formed and the fibers are completely encapsulated, this process could produce a surface of required topological roughness that is useful for coatings.[19] A successful PyC deposited on CVD SiC has 
been demonstrated and occurred via a fluidized bed reactor at ORNL.

\subsection{ELECTROLYTIC CHROMIUM OR "HARD CHROME"}

In electrolytic deposition, a stabilized solution of the metal ions undergoes a reaction on the substrate, and deposits ground state metal atoms. In chromium, this known as "hard chrome plating". Colloquial terms for electrolytic chromium are myriad and descriptive e.g. "hex chrome", "hard chrome", "industrial chrome" or "bumper chrome" rather than scientific. Figure 2 shows a schematic of the process.

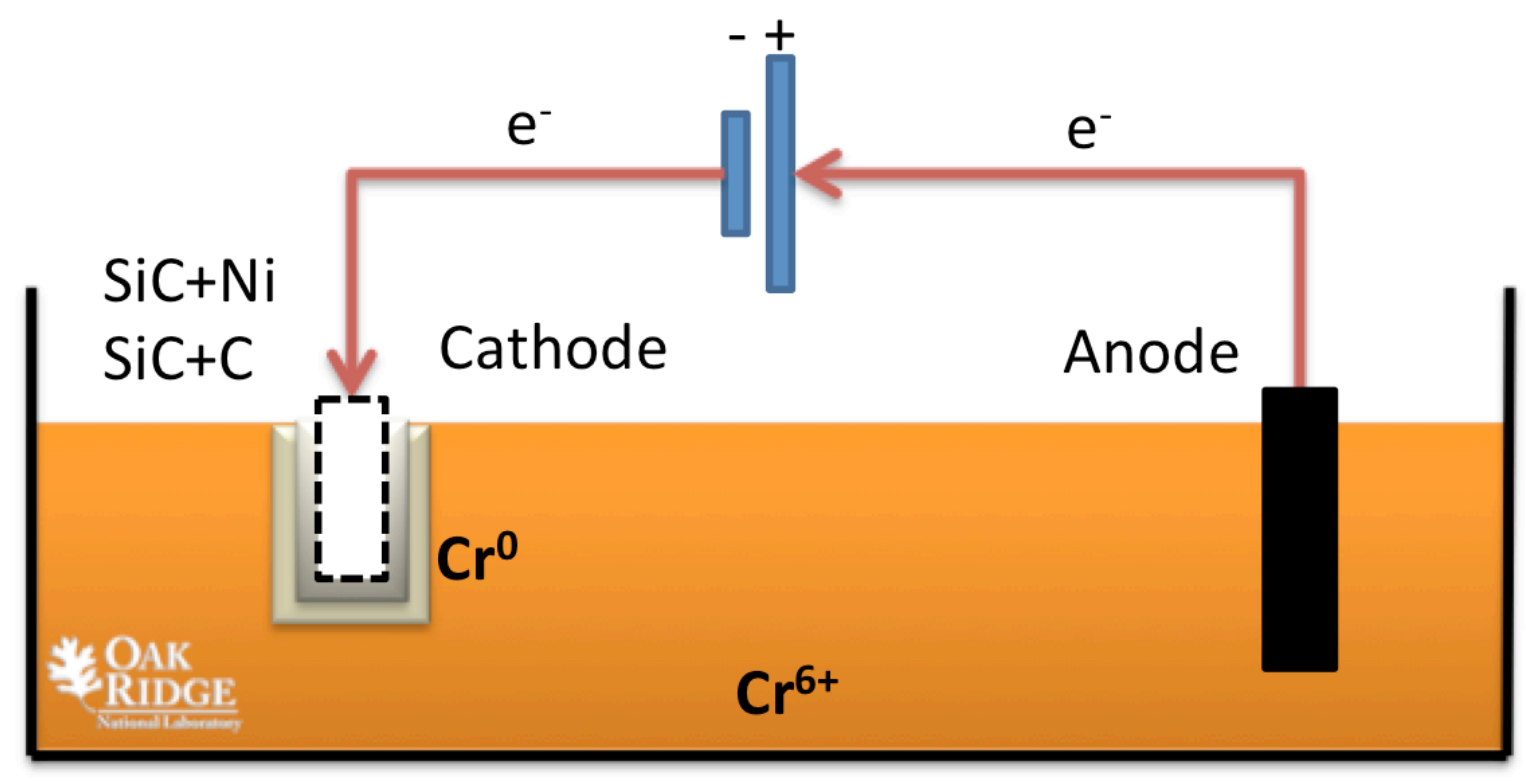

Figure 2. Schematic of electrolytic chromium plating. A power source provides electrons to the stabilized chromium ions, which are reduced and coat on the substrate.

In the electrolytic process, the reduction of $\mathrm{Cr}$ ions is caused by the external power source supplying electrons to the substrate which acts as a cathode. The substrate must be an ohmic conductor, because the efficiency of deposition depends on the surface resistance. The hard chrome process is designed to improve substrate wear resistance, so deposited "hard chrome" has had several decades of alloy design for hardness and internal microcracks for lubricant retention. Process time is about an hour and typical thickness is $\sim 5$ to $50 \mu \mathrm{m}$.

\subsection{CATHODIC ARC PHYSICAL VAPOR DEPOSITION}

In cathodic arc physical vapor deposition (PVD), a metallic target (usually cylindrical) is physically evaporated by an arc discharge in high vacuum caused by a bias voltage. The substrate is placed in front of the target, resulting in metallic atoms travelling from the target to the substrate. Figure 3 shows a schematic of the process. 


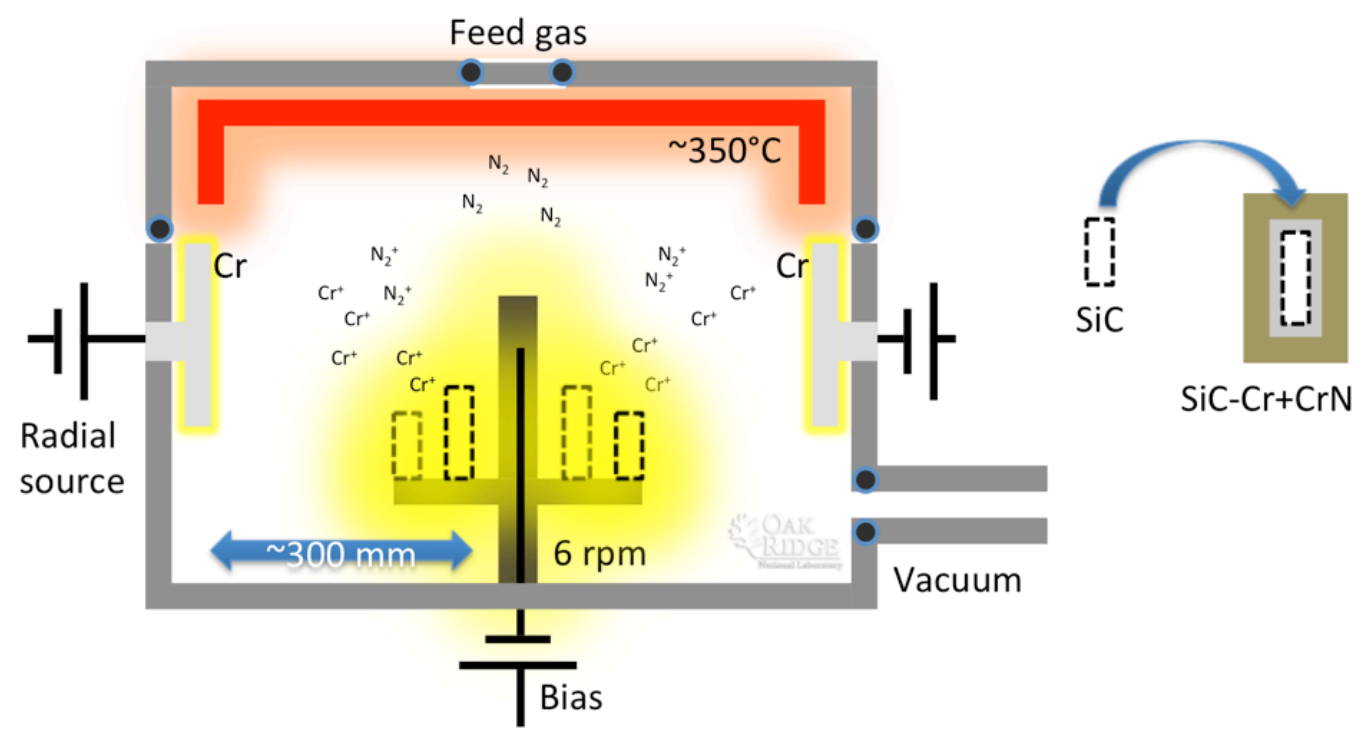

Figure 3. Schematic of Cathodic Arc Physical Vapor Deposition (PVD) of metal and metal nitride. The metal is physically evaporated and electrostatically forced to impact on the substrate.

The source of the coating is any metal that can be made into a disc-shaped target and connected to an electric current. In addition, metallic nitrides can be formed by ionization of inert gases such as $\mathrm{N}_{2}$ deposited with the metal. These coatings are designed to have high wear and corrosion resistance. Process time is several hours and typical thickness is $\sim 2$ to $20 \mu \mathrm{m}$.

\subsection{VACUUM PLASMA SPRAY}

In vacuum plasma spray (VPS), the metallic coating is initially a powder, and is dispersed through a heated plasma gun using an inert carrier gas. The powder rapidly cools on the substrate. Figure 4 shows a schematic of the VPS process.

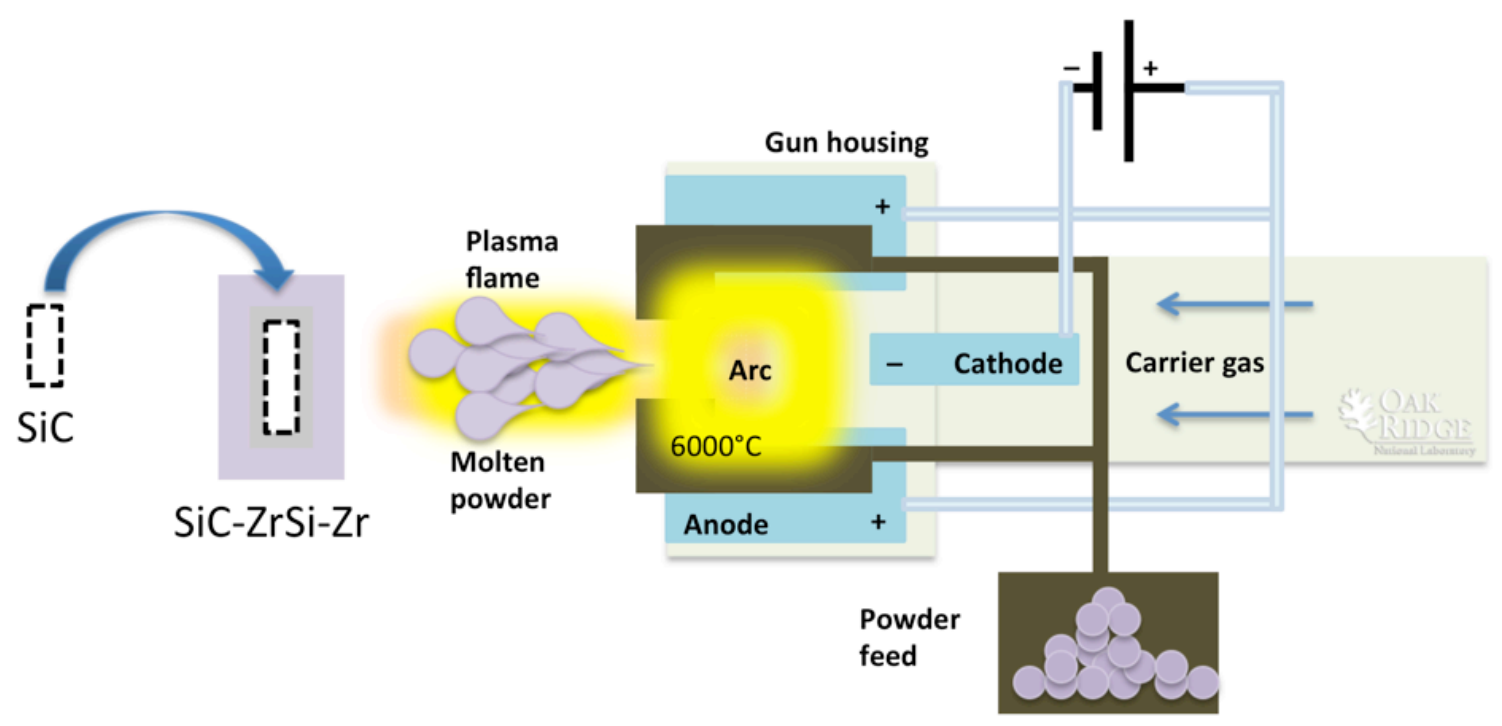

Figure 4. Schematic of the process of VPS of metallic coatings and metal nitride variants. 
The deposited coating can theoretically be any metallic element, but $\mathrm{Zr}$ and $\mathrm{Cr}$ are currently the selected materials.[20] The hot plasma can assist in surface ablation providing anchor and pitting for the coating to deposit. VPS is designed for large size applications for bulk coatings for wear resistance, ablation and oxidation.[21] The processing time is about an hour and typical coatings are in the order of $\sim 50$ to $150 \mu \mathrm{m}$.

\subsection{CHARACTERIZATION}

The coated $\mathrm{SiC}$ specimens were characterized by $\mathrm{X}$-ray diffraction (XRD) using $\mathrm{Cu}$ Ka radiation using a Bruker D2 X-ray diffractometer $(30 \mathrm{kV}, 20 \mathrm{~mA})$. The samples were mounted on a zero-background (SiO2 Optical Grade from MTIXTI) XRD sample mount. Residual deposit stress analysis was conducted (by ASTM B975). After plating, specimens were mounted and polished to $0.5 \mu \mathrm{m}$ diamond finish. Deposition thickness was measured based on SEM imaging. SEM imaging of cross-section samples shown were analyzed using a JEOL6500F SEM.

\subsection{MODELING}

Zirconium does not have significant depletion effects but historic experience with steel-based fuel cladding has indicated that the presence of nickel in nuclear reactors hinders neutron economy due to parasitic absorption removing thermal neutrons from the core that would otherwise have been available to induce fission reactions. In considering the practical application of the nickel-based coating, it is of interest to estimate the penalty to the cycle length of a typical LWR core when the proposed coating is introduced, which has been conducted on several systems.[22-24] To this end, computational models of typical LWR fuel assemblies are constructed for analysis with the SCALE6.1 code suite.[25] The T-DEPL sequence of the TRITON module is employed for this study to simulate depletion of individual fuel assemblies to a burnup of about $60 \mathrm{GWd} / \mathrm{MT}$ for cases of varying enrichment and nickel coating thickness. Following these simulations, the linear reactivity model is used to extend the single-assembly results to a typical 3-batch LWR core so as to glean a realistic estimate of the impact of assembly enrichment and coating thickness on cycle length.

Table II details the fuel assembly geometry and operating conditions imposed on the SCALE models. The 2D fuel assembly models are based on a Westinghouse 17x17 PWR assembly, and the simulated operating conditions are selected to be representative of a PWR core environment. Some operating conditions such as material temperatures and specific power were assumed based on typical PWR parameters and other similar fuel assembly depletion simulations in literature.

Table II. Fuel Assembly Geometry and Operating Conditions

\begin{tabular}{|l|l|}
\hline Assembly Array & $17 \times 17$ \\
\hline Guide Tubes per Assembly & $25(=24$ control rods + 1 instrument tube $)$ \\
\hline Specific Power & $40 \mathrm{MW} / \mathrm{MT}$ \\
\hline Fuel Temperature & $900 \mathrm{~K}$ \\
\hline Fuel Rod Pitch & $1.26 \mathrm{~cm}$ \\
\hline Fuel Pellet Radius & $0.4096 \mathrm{~cm}$ \\
\hline Fuel Clad Temperature & $600 \mathrm{~K}$ \\
\hline Fuel Clad Outer Radius & $0.4750 \mathrm{~cm}$ \\
\hline Fuel Clad Thickness & $0.0572 \mathrm{~cm}$ \\
\hline He Gap Temperature & $600 \mathrm{~K}$ \\
\hline
\end{tabular}




\begin{tabular}{|l|l|}
\hline Guide Tube Outer Radius & $0.6121 \mathrm{~cm}$ \\
\hline Guide Tube Thickness & $0.0406 \mathrm{~cm}$ \\
\hline Coolant Temperature & $600 \mathrm{~K}$ \\
\hline Coolant Density & $0.70 \mathrm{~g} / \mathrm{cm}^{3}$ \\
\hline
\end{tabular}

Fuel enrichment was varied from $3 \%$ to $5 \%$, and the nickel coating thickness was varied from 0 to $40 \mu \mathrm{m}$. In all cases with the nickel coating, the chromium layer thickness was kept at a constant $30 \mu \mathrm{m}$.

Table III details the case matrix for the study; in addition to the SiC assemblies, a case was run with Zircaloy-4 cladding of standard Westinghouse-type 17x17 PWR fuel assembly dimensions to provide a fundamental reference. Reflective boundary conditions are imposed on all fuel assembly models, thereby approximating infinite lattices.

Table III. Case Matrix

\begin{tabular}{|l|l|l|l|l|}
\hline Case ID & Clad Material & Enrichment (\%) & Ni Thickness & Cr Thickness \\
\hline 1 & Zircaloy-4 & 4.00 & 0 & 0 \\
\hline 2 & SiC & 4.00 & 0 & 0 \\
\hline 3 & SiC & 4.00 & 20 & 30 \\
\hline 4 & SiC & 3.00 & 0 & 0 \\
\hline 5 & SiC & 3.00 & 40 & 30 \\
\hline 6 & SiC & 5.00 & 0 & 0 \\
\hline 7 & SiC & 5.00 & 40 & 30 \\
\hline
\end{tabular}

Each fuel assembly model was depleted to about $60 \mathrm{GWd} / \mathrm{MT}$, and the assembly reactivity was tracked at each burn step. Assembly discharge is assumed to occur when the reactivity reaches 0.03 , accounting for an assumed neutron leakage of $3 \%$ that is not captured by the infinite lattice models. 


\section{EXAMINATION OF COATINGS}

\subsection{SUBSTRATE MODIFICATION}

The tensile stresses after depositing were present in all coated materials. This was observed by microcracks normal to the substrate (transverse) or peeling. Fundamental thin film theory explains that during deposition, the substrate-coating interface is initially constrained: as the atoms in the coating re-arrange, the coating shrinks - by densification (elimination of grain boundaries), incorporation of segregated atoms, differential densification (the surface is under more tensile stress than the bulk), lattice misfit or a coefficient of thermal expansion (CTE) mismatch during temperature change.[26-34] Figure 5 shows the residual tensile stresses in coatings obtained from different processes, and other $\mathrm{Cr}$ deposits as a function of coating thickness.

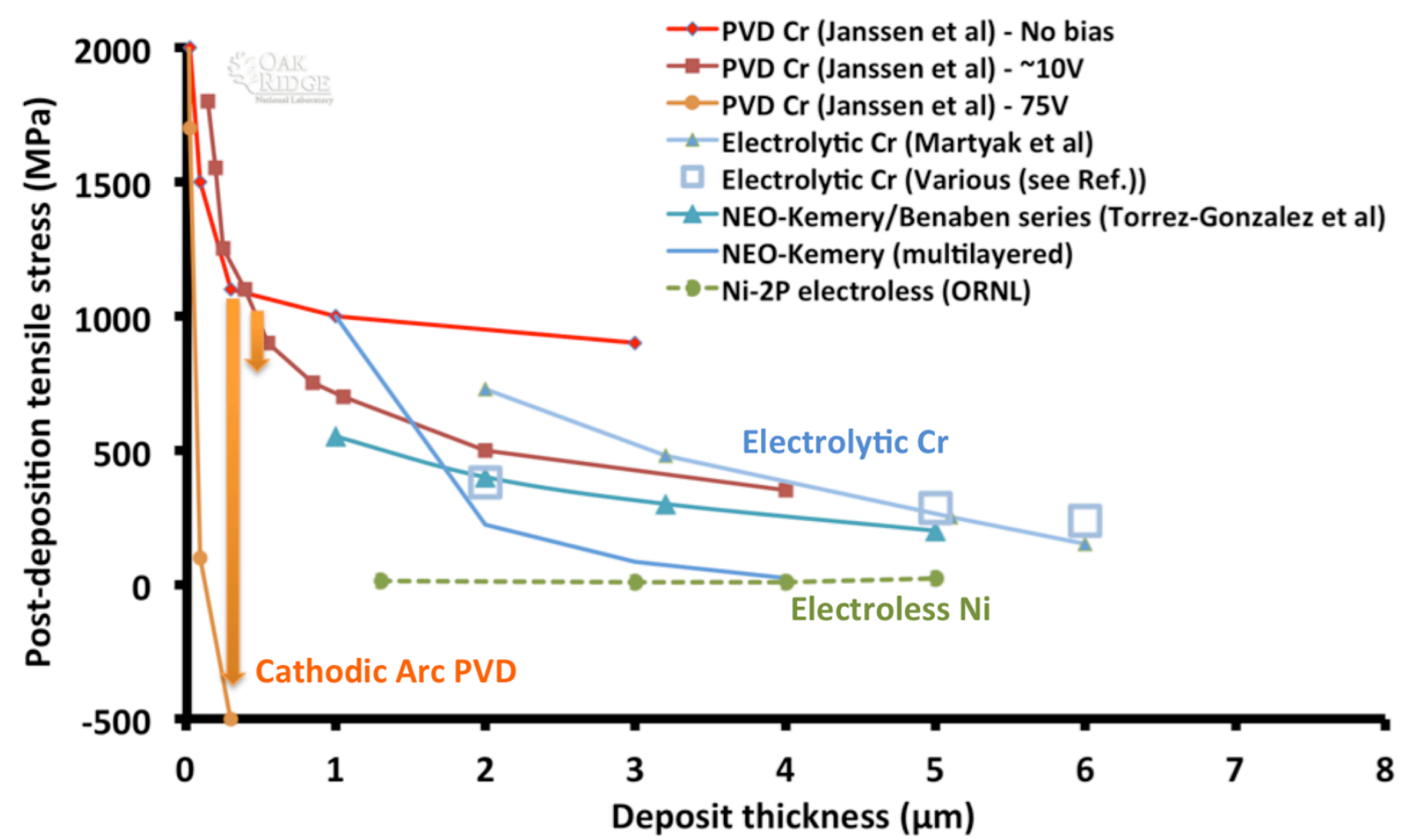

Figure 5. Tensile stresses of as-deposited coatings of $\mathrm{Cr}$ and Ni via PVD, electrolytic and electroless methods. [26, 27, 32, 34, 35] (adapted from Ang et al.[36]) PVD can mitigate coatings by increasing voltage bias.

Figure 5 shows that all coatings have the same trends of significant tensile stresses at the early stages of deposition, and this stress decreases with thickness. In hard, low ductility metals such as bcc-Cr, a decrease in stress appeared to be caused by plastic deformation in the form of microcracks.[26, 37] Correlation was found between all four $\mathrm{Cr}$ methods, including two verifications with electrodeposited (NEO-Kemery and Kemery-Benaben type) chromium. Cracks were also found in early VPS $\mathrm{Cr}$ attempts. This indicates an intrinsic behavior from the microstructure of chromium metal.

In PVD coatings, the application of a bias voltage accelerates $\mathrm{Cr}$ ions toward the substrate. This is known as ion peening, and results in coating that has an upper surface of amorphous regions and a high density of planar defects, compressing the surface and countering tensile stresses.[27, 38-45] Data from Janssen et al is shown in Figure 5; as the bias voltage was increased from $10 \mathrm{~V}$ to $75 \mathrm{~V}$, the compression was sufficient to 
change the sign of residual stress to compressive. Typical PVD coatings are compressive to several GPa.[27, 46]

The electroless coating of Ni-P deposited with no residual stresses, since the deposited metal was fcc-Ni and has higher ductility than hcp/bcc metals. This indicated that depositing a different metal composition may alter the way the coating deforms as thickness increase. This shows that the tensile stress results in peeling of the coating, deforming cohesively or maintaining the coating-substrate interface by microcracking.

Since a combination of both peeling and microcracking was observed in early electrolytic coatings, the modification of the interface was conducted as a mitigation strategy. The interface was improved by surface roughness. Surface roughness increases the mechanical interlocking between coating and substrate, and is able to convert tensile stresses into compressive stresses (e.g. if deposited in a concave region).

It was apparent that machined surfaces of cut and abraded coupons showed successful electrolytic chromium deposition, whereas the unroughened side showed significant peeling. Figure 6 shows an example of an early $\mathrm{SiC}_{\mathrm{f}}$-SiC composite with an electrolytic chromium coating. The image on the left shows dark regions of the $\mathrm{SiC}_{\mathrm{f}}$-SiC unmachined surface where the coating peeled, and many cracks are visible in the regions of coating that remain. However, the machined side of the coupon on the right of Figure 6 shows that the coating has adhered to the surface. This did not indicate the absence of cracks since these are only visible in electron microscopy. However, it indicated that despite any flaws in the coating, the tensile stress was not able to remove the coating from the surface. This was a key indicator that with proper surface preparation, the tensile stresses could be mitigated.

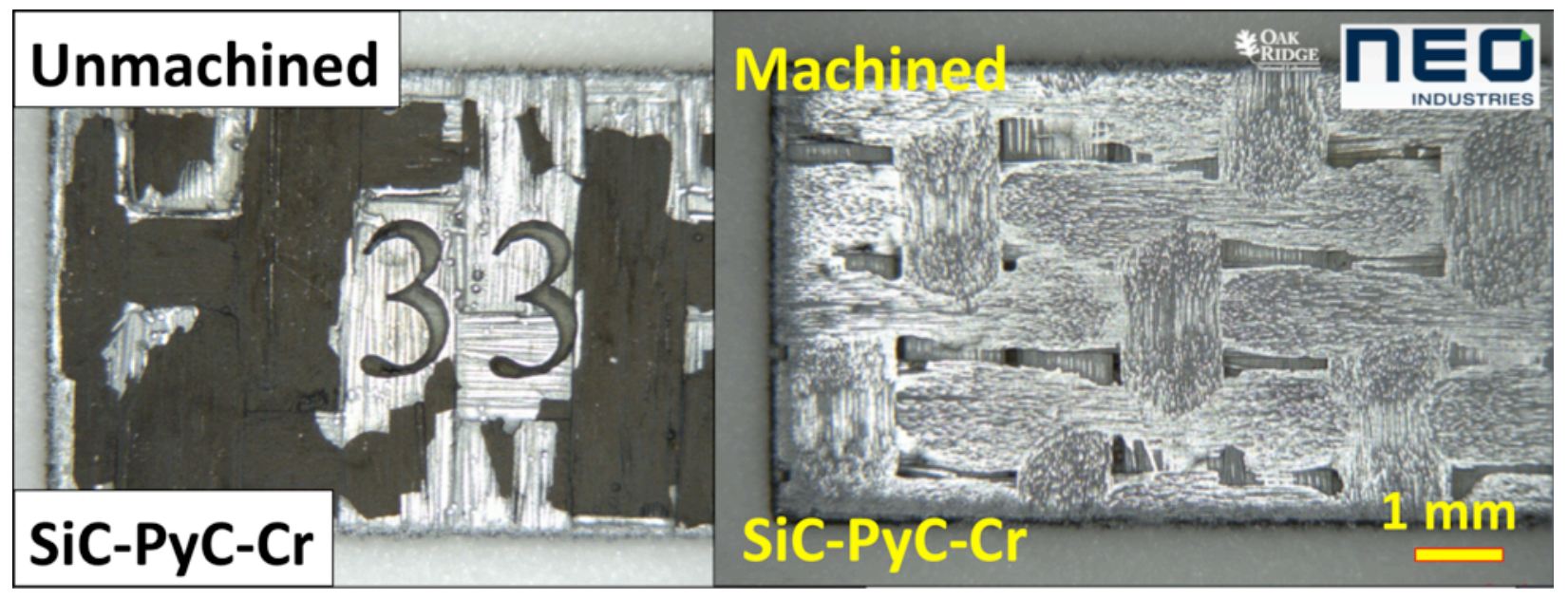

Figure 6. Optical microscopy images showing the result of unmitigated tensile stresses from electrolytic chromium deposited on unmachined and machined SiC surfaces.

Surface preparation techniques were examined. Figure 7(a) shows an SEM image of the approximate surface roughness after a typical $25 \mu \mathrm{m}$ diamond abrasion that would be found after machining and grinding. However, since fuel rods cannot be mechanically abraded, other techniques were developed to improve surface roughness.

Using an acid and alkali etching, Figure 7(b) shows CVD SiC material that was designed to provide an equivalent morphology to mechanical abrasion. As a proof of principle, this demonstrated the surface roughness could be matched between machining and chemical etching. All successful electrolytic chromium 
coatings were plated on surfaces with high level of surface roughness. This surface preparation could also be used to improve PVD and VPS coatings.

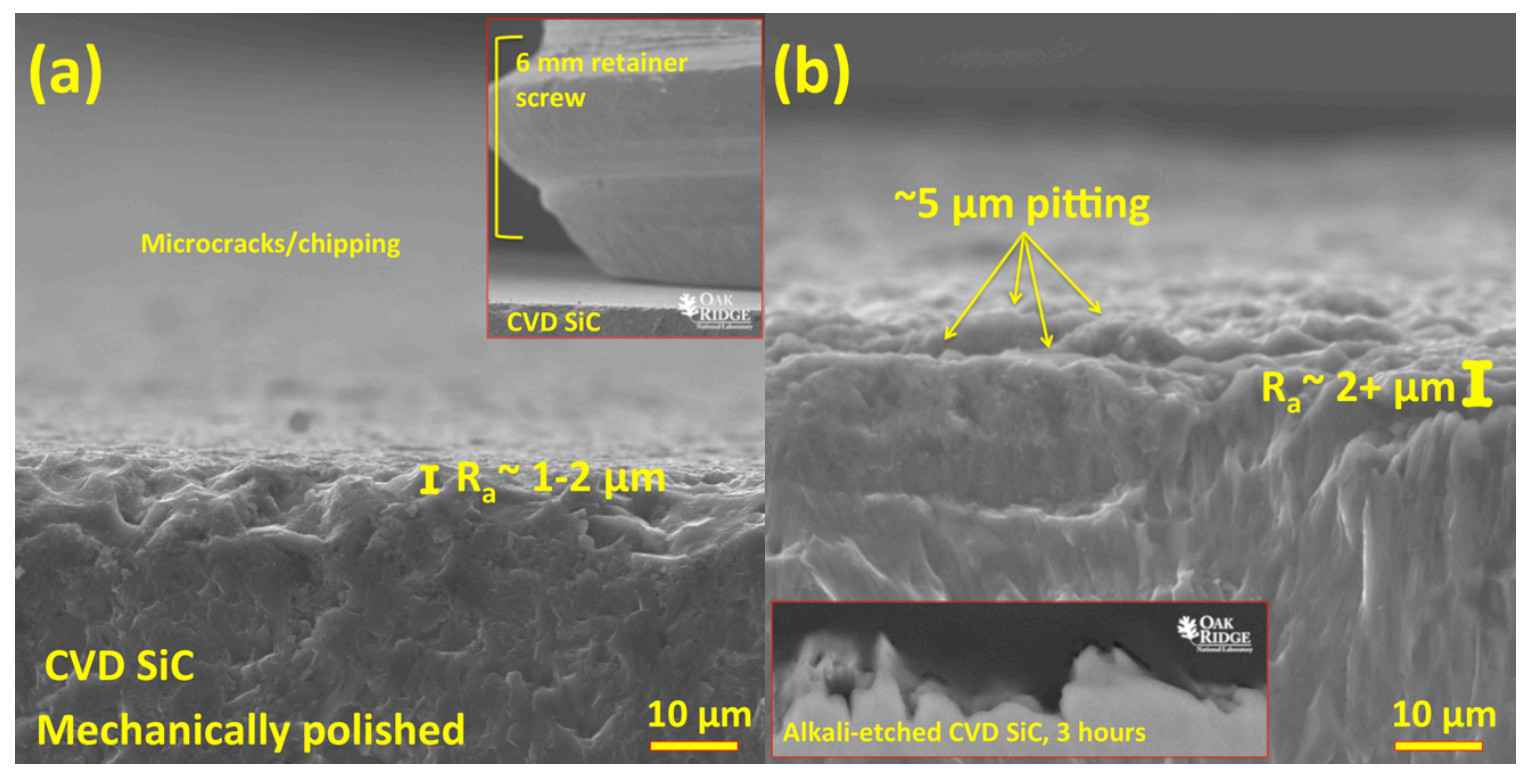

Figure 7. Two examples of surface preparation of CVD SiC for coating. Note that samples were side-mounted (see inset in (a)) and show the edge of sample to observe (a) mechanical polishing adding surface roughness. This also includes microcracks that appeared to be visible when the image plane was moved. No microcracks were observed by (b) alkali etching, which added roughness with pitting, and the inset in (b) shows the surface morphology when cross-sectioned.

Finally, the ideal surface preparation technique would be to produce cladding with a roughened surface. This would use dedicated CVD capability, using in-situ addition of pyrolytic carbon (PyC) as a graded interface between $\mathrm{SiC}$ and PyC.[19] A graded interface can be demonstrated by Figure 8. 


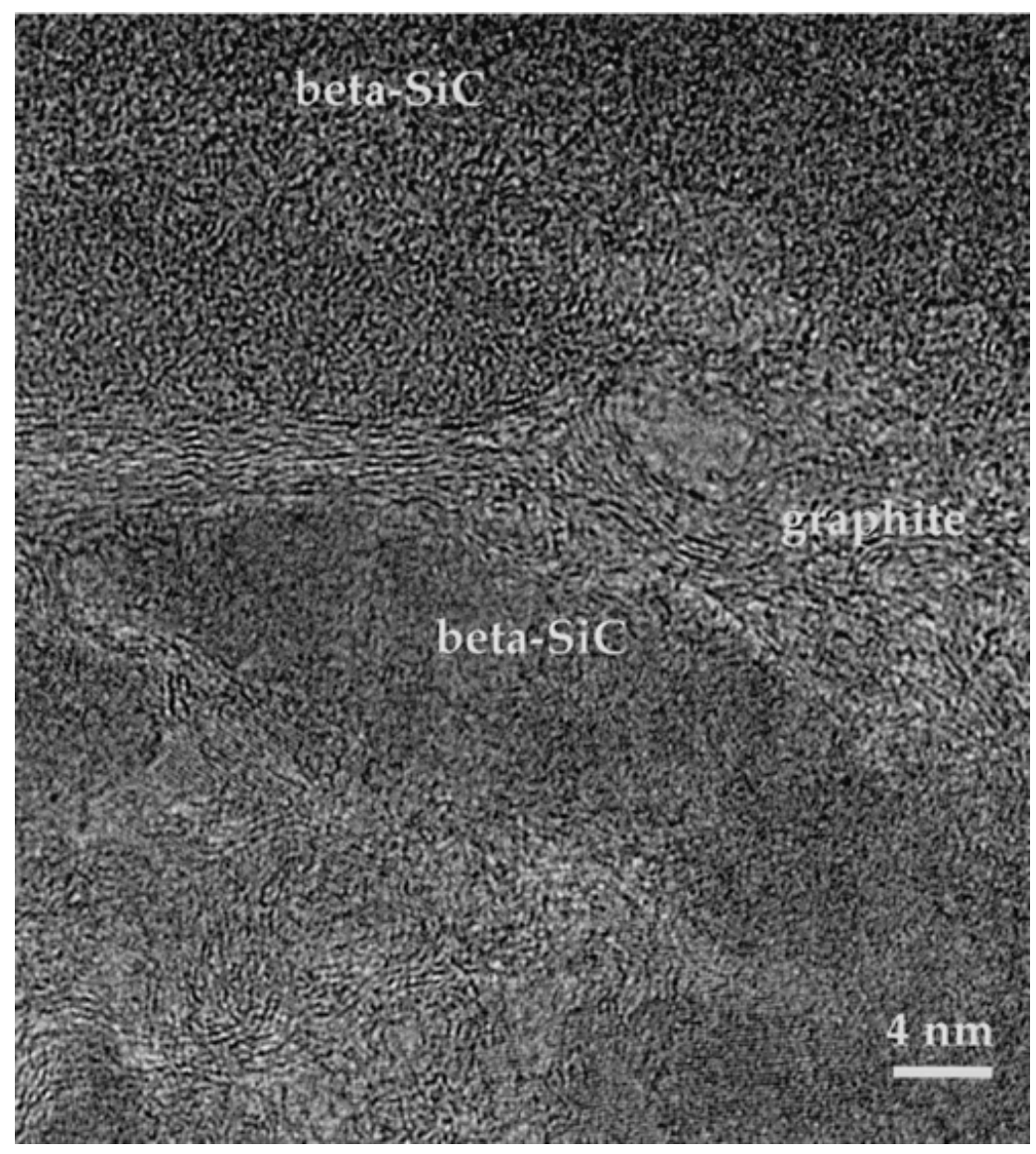

Figure 8. High resolution TEM image of a porous SiC-to-PyC interface, showing distinct phases of SiC and the graphite (PyC) from Snead et al.[19] Reproduced with permission.

Figure 8 shows $\mathrm{SiC}$ and $\mathrm{PyC}$ as a composite, and the phase separation indicates that the carbon could be etched by thermal or chemical methods, and provide purchase for a coating. The upper PyC layer is conductive and could be used to deposit chromium. However, industrial vendors no longer invested in CVD/CVI capability, and thus a temporary method was used to demonstrate surface roughness mitigation of tensile stresses. Future work on substrate preparation will continue to pursue graded interface capability as an umbrella preparation method on all CVD SiC materials.

\subsection{COATINGS ON SILICON CARBIDE}

After appropriate surface preparation, materials were coated by PVD, VPS and electrolytic Cr. The coatings are described in the order of their ability to mitigate tensile stresses without coating damage. This qualitatively indicates their level of readiness with the leading candidates shown first.

\subsubsection{Cathodic Arc Physical Vapor Deposition}

In PVD methods, the ion peening mechanism counters tensile stresses (Figure 5) and no surface preparation appeared necessary. Figure 9(a) shows the morphology of PVD $\mathrm{Cr}$ when deposited on an electroless Ni bond coat. The coating is a $\sim 20 \mu \mathrm{m}$ layer above the $\mathrm{SiC}_{\mathrm{f}}-\mathrm{SiC}$ fibers and the brighter Ni phase. The $\mathrm{Ni}$ bond coat was included as an option to investigate interface bonding. Samples without a $\mathrm{Ni}$ bond coat are identical to Figure 
9(a) but show the absence of a brighter interface in SEM images.

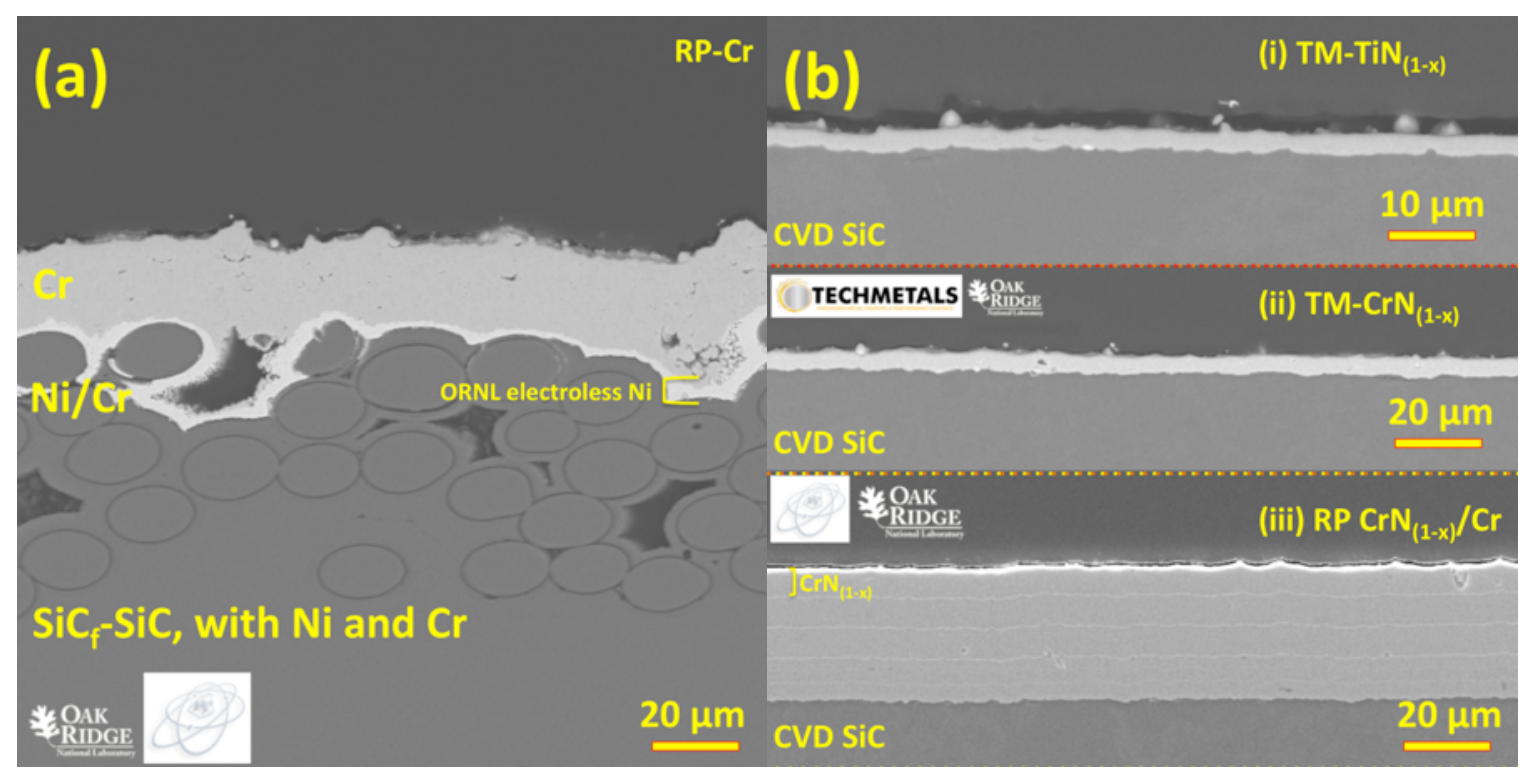

Figure 9. PVD coatings on SiCf-CVD $\mathrm{SiC}$ and CVD $\mathrm{SiC}$ by several industrial vendors showing (a) $\mathrm{Cr}$ from Richter Precision (RP) and (b) metal nitrides (i) TiN from Techmetals (TM), (ii) $\mathrm{CrN}$ (TM) and (iii) multilayer $\mathrm{CrN} / \mathrm{Cr}$ from RP. Little to no surface preparation is required for PVD, but it requires a significant cycle time and may be expensive to scale.

Figure 9(b) shows three nitride-based PVD coatings. All can be deposited as a single, or multilayer system. The coating in (i) shows $\operatorname{TiN}_{(1-x)}$ as a single layer, (ii) $\operatorname{CrN}_{(1-x)}$ as a single layer and (iii) $\operatorname{CrN}_{(1-x)}$ as a multilayer coating interleaved with Cr. XRD patterns (not shown) indicate the CVD SiC was coated with a mixture of chromium metal and metal nitrides with crystallite sizes $\sim 5-15 \mathrm{~nm}$ and significant microstrain. This was consistent with the ion peening effect compressing tensile stresses associated with coating densification and annealing.[27, 32, 34] No surface flaws were visible by optical or electron microscopy. PVD occurs at 350$400^{\circ} \mathrm{C}$, which provides modest thermal annealing of the tensile stresses and moderates the CTE mismatch.

PVD metallic nitrides in Figure 9(b) are less expensive than pure metallic deposition and became a substitute for industrial hard chrome during environmental concerns of hexavalent chromium of the 1970s. However, the coefficient of thermal expansion (CTE) of nitrides (TiN, CrN) are substantially higher than $\mathrm{SiC}$, and their moduli indicate they are stiff materials. The irradiation response of TiN and $\mathrm{CrN}$ are unknown. The metallic $\mathrm{Cr}$ system is considerably more attractive due to the low CTE, lower modulus, known irradiation behavior and ductility at $\sim 320^{\circ} \mathrm{C}$.

The prospect of industrial PVD is limited because process time is in the order of several hours, and scaling to fuel rod geometries would involve substantial capital. PVD $\mathrm{Cr} / \mathrm{CrN}$ coatings have been attempted with success on nuclear cladding such as Zircaloy-4[47], but further investigation on a SiC substrate is needed. In considering scaling, PVD is currently used to coat 8-foot cutting tools in rotisserie process, but the investment and turnover rate for a million fuel rods per year would be in the order of a nine-figure sum.

\subsubsection{Vacuum Plasma Spray}

Figure 10 shows the VPS coating cross-section morphologies from Plasma Processes, LLC. The morphology of 
the coating (bright phase) is shown in Figure 10(a), and the dark region is CVD SiC. In the brighter coating region, there is some porosity due to trapped gas molecules, and interface stresses appear to be tensile given that that transverse cracks are observed on the SiC interface. There is a lack of "fusion defects", which are referred in this report as "unmelted particles". Since particles retained original morphology, this implied the absence of diffusion or melting. The absence of a diffusion couple also indicates a rapid cooling took place, suggesting grain boundary and lattice diffusion also could not have sealed the pores. The combination of these two factors suggests that the pores are interconnected, which could be a problem during corrosion.

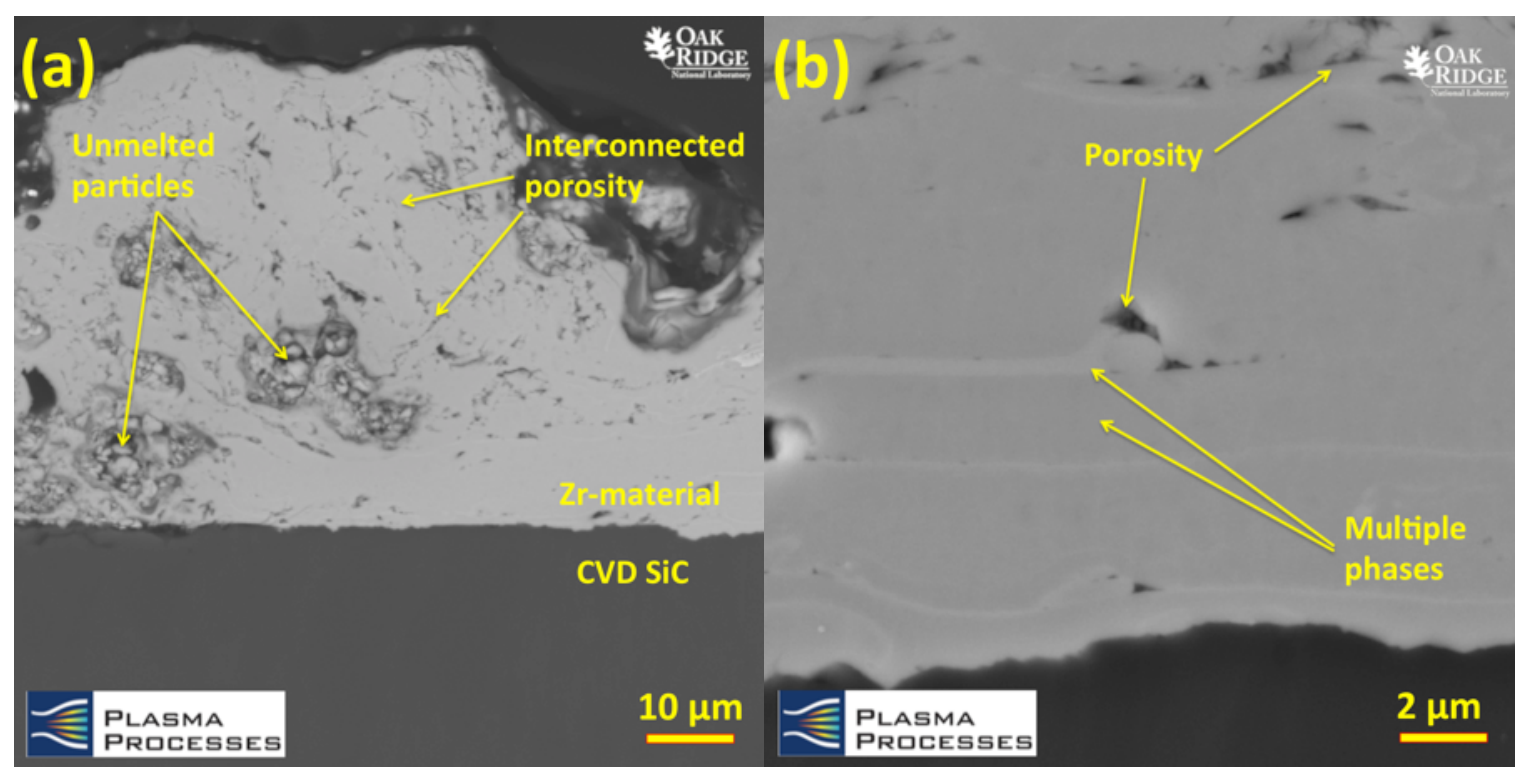

Figure 10. VPS coatings on CVD-SiC showing (a) general morphology of Plasma Processes, LLC coating and (b) interface morphology of VPS Zircaloy-2 powder on CVD SiC.

Figure 10(b) shows a higher magnification region of the coating interface to CVD SiC. It shows that most of the coating is a darker phase in BSE imaging, which indicates lower Z-atomic weight. The brighter lamellar are either a higher atomic weight, or the result of channeling contrast. In either case, this represents at least two phases and cannot be nuclear-grade Zircaloy-2.

The XRD patterns are shown in Figure 11 with the unreacted Zircaloy-2 powder shown in the faint watermark pattern (a). The powder feed was $\alpha-Z r$ and microstrain and crystallite size (not shown) were typical for annealed powders. 


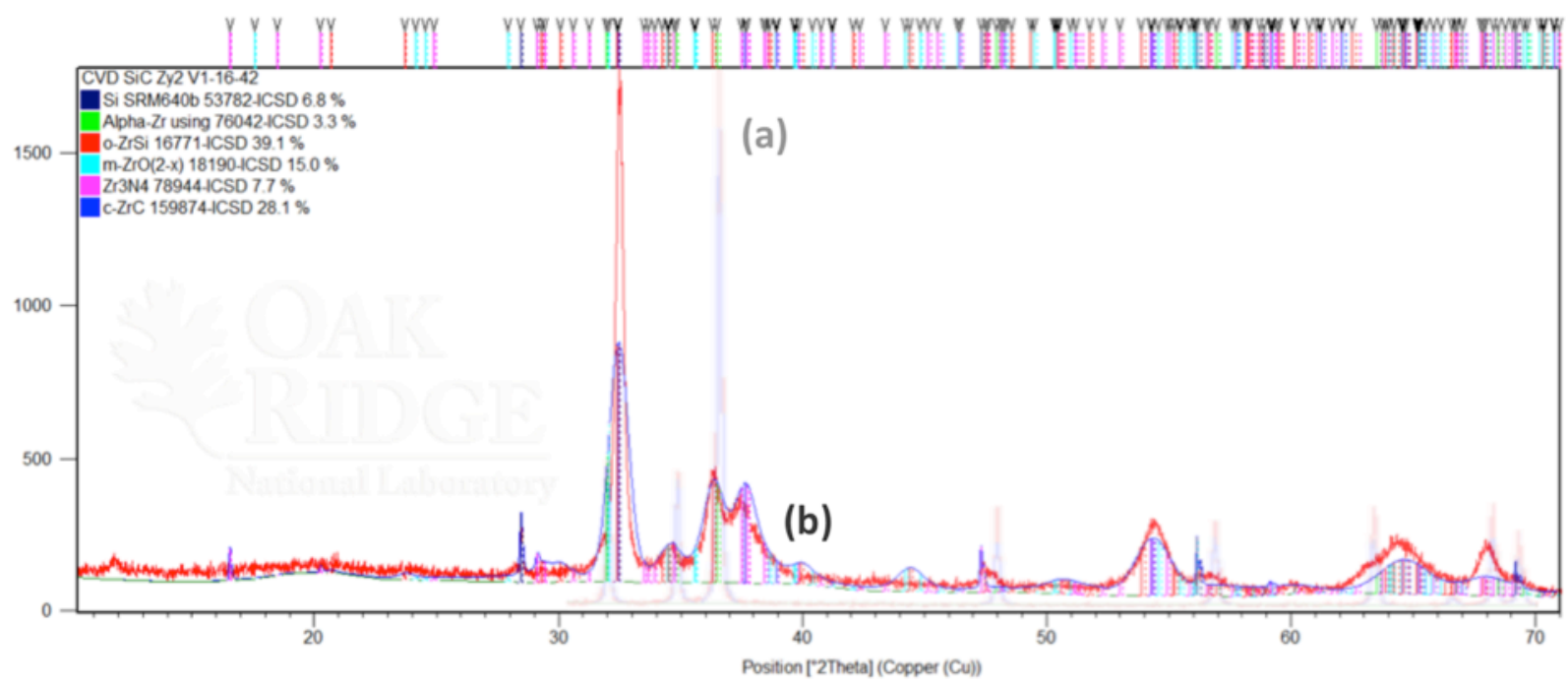

Figure 11. XRD pattern of Zircaloy-2 (a) raw powder and (b) sprayed on CVD SiC. Phases and approximate quantitative phase analysis of the coating is shown.

Figure 11(b) shows the XRD pattern of VPS sprayed powder. It is obvious that there is a change in the XRD pattern when overlaying (a) on (b) in Figure 11. Pattern fitting was conducted after both $\alpha$ and $\beta$-Zr phases did not match. Patterns were manually searched and refined based on several possible reactions with $\mathrm{Si}, \mathrm{C}, \mathrm{O}$ and $\mathrm{N}$. The major phases were identified as c- $\mathrm{ZrC}_{(1-\mathrm{x})}$ and o-ZrSi. Some phases of $\mathrm{Zr}_{3} \mathrm{~N}_{4}, \mathrm{~m}-\mathrm{ZrO}_{2}$ and $\mathrm{Zr}$ metal appear to be present in small amounts.

This correlates to SEM/BSE results in Figure 10, since two regions of different contrast indicate regions of different atomic weight atoms. The presence of unmelted particles agreed with the supposition that the coating was ceramic Zr rather than metallic Zr. This indicated that most of the coating powder reacted with the substrate SiC during processing. The absence of a diffusion couple suggested an ablative mechanism during the plasma spray, which may have reacted with the $\mathrm{Zr}$ powder. While it indicates no surface diffusion or phases that cannot diffuse at the process temperature, it also implies that surface preparation is not required for VPS coatings because surface roughening is conducted in-situ.

Currently, the main concern is the reaction of the $\mathrm{Zr}$ powder in plasma environment with $\mathrm{SiC}$ to form c-ZrC and o-ZrSi. A secondary concern is atmosphere control due to the high enthalpy and kinetics of $\mathrm{O}^{2-}$ reactions. Further development is required to preserve the Zircaloy-2, which is one of the attractive features of this mitigation coating. Finally, scaling and surface texture need to be addressed should the coating prove feasible.

\subsubsection{Electrolytic chromium or "hard chrome"}

Chromium was deposited by electrolytic method on CVD SiC and $\mathrm{SiC}_{\mathrm{f}}-\mathrm{SiC}$ coupons. Chromium from NEO Knoxville, LLC was a variant of industrial "hard chrome", which responded by microcracking relief of the tensile stresses (Figure 5).

Two examples of hard chrome on SiC are shown in Figure 12. In (a) the main SEM image shows a small layer of $\mathrm{Cr}$ deposited on $\mathrm{Ni}$. The $\mathrm{Ni}$ was deposited on an etched $\mathrm{SiC}$ surface. The Ni was able to deposit within the pitted surface of the $\mathrm{SiC}$ coupon and provided interlocking with the substrate. This was caused by the tensile stress of $\mathrm{Cr}$ depositing on $\mathrm{Ni}$, which is usually dissipated at $\sim 2 \mu \mathrm{m}$ (Figure 5). Without the etching and pitting, 
the chromium usually debonds the nickel from the SiC surface. Note that some regions within the pits still show debonding, presumably of the $\mathrm{Cr}$ attempting to remove the $\mathrm{Ni}$ at the $\mathrm{Ni}$-SiC interface.

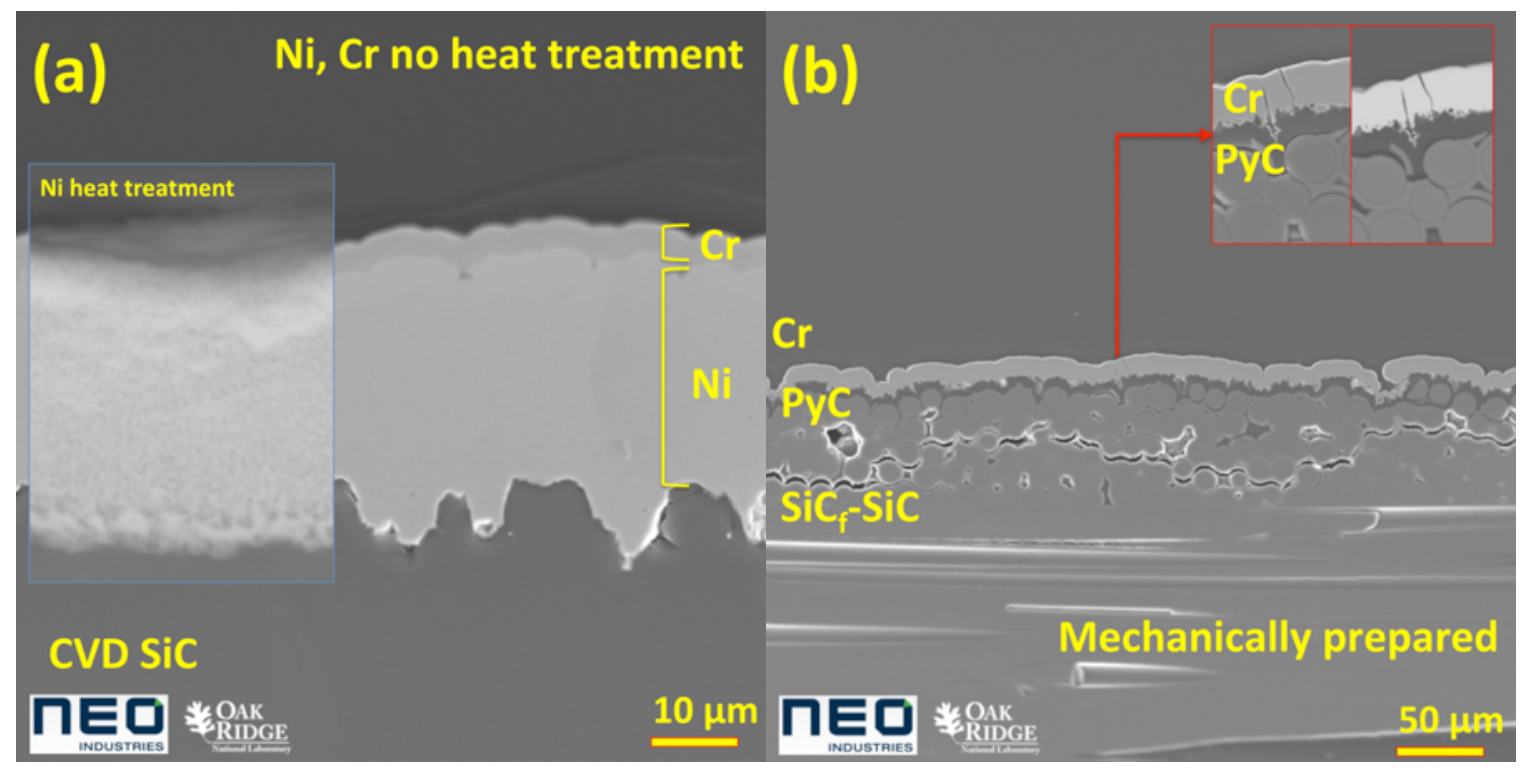

Figure 12. "Hard chrome" plating by NEO Industries on (a) SiC-Ni with $\mathrm{Cr}$ on CVD SiC (b) pyrolytic carbon bond-coat on $\mathrm{SiC}_{\mathrm{f}}-\mathrm{SiC}$, which has a layer of chromium. The inset shows an example of the microcracking problem.

The inset "Ni heat treatment" in Figure 12(a) shows a second option where the $\mathrm{Ni}$ is heat treated to bond the $\mathrm{Ni}$ and $\mathrm{SiC}$ together. $\mathrm{Cr}$ is then deposited on the Ni. This option can improve the bond between $\mathrm{SiC}$ and $\mathrm{Ni}$, such that the tensile stress of $\mathrm{Cr}$ deposition does not remove the coating. However, there are limitations to diffusion bonding such as CTE mismatch and the ductility of the interphase (see Post-processing).[48]

There is another process to deposit hard chrome plating without using nickel. Deposition of pyrolytic carbon on $\mathrm{SiC}$, followed by chromium on $\mathrm{PyC}$, results in $\mathrm{SiC}_{\mathrm{f}}-\mathrm{SiC} / \mathrm{PyC} / \mathrm{Cr}$. Figure 12 (b) shows an example of $\mathrm{SiC}_{\mathrm{f}^{-}}$ $\mathrm{SiC} / \mathrm{PyC} / \mathrm{Cr}$ morphology. The chromium is the brighter layer $\sim 20 \mu \mathrm{m}$ thick. The PyC is the dark layer on top of the fiber-reinforced composite. In this material, the tensile stresses appeared mitigated, and the chromium was plated to the thickness that simulated the requirements of fuel cladding. Note that tensile microcracking is still difficult to mitigate - the inset in Figure 12(b) shows an example of the microcracking in "hard chrome", which appears as transverse cracks through the coating. The tensile stress appears to have caused damage in the composite itself, shown by the horiztonal crack. Phase analysis by XRD (not shown) indicated the phases were $\mathrm{SiC}, \mathrm{Ni}$ and $\mathrm{Cr}$.

Since only destructive cross-sectioning (such as that in Figure 12) can prove the absence of microcracks, this becomes a reliability and quality control issue. The current mitigation strategy is to demonstrate feasibility by alternating depositions of $10 \mu \mathrm{m}$ Cr to seal each successive microcracked layer. A second option being pursued is to completely prevent microcracking as a mechanism. Figure 5 shows how this could be designed. Since strain is fixed, only the microstructure and modulus can be changed. While creep and radiation-induced creep is likely to help in alleviating stresses, this cannot be investigated at this stage. Instead, the tensile stresses from $\mathrm{Cr}$ could be countered by alloying, designing for a lower modulus and changing the ductility, thus instead of microcracking, it could have a tensile stress deposition profile closer to that of the electroless nickel in Figure 5. The development of "soft chrome" can be based upon composites or alloys (e.g. Cr-30\%Ni). 
In preparation for a new alloy, attempts are underway to reduce the thickness of $\mathrm{Ni}$ and determine the composition limit (see Fuel Assembly Depletion Simulations). If the deposition can use "soft chrome" where deformation by microcracking is eliminated, this would be the most economical, fastest, scalable, and most corrosion resistant option, and could be adjusted for composition in the future.

\subsubsection{Post-processing}

Heat treatment is designed to induce diffusion between the interface of the coating and substrate phase. Ideally, this removes morphological features such as pores and cracks that typically represent stress concentrations, and encourages intermixing and chemical bonding of two or more elements to create interphases. While it adds an additional processing step, it should provide an interface of higher strength, increases reliability and provides a larger region to distribute CTE mismatch stresses.

Two key aspects were investigated with regard to heat treatment as a strengthening mechanism. First, CTE mismatch is crucial because coatings have two interfaces, one of which is not bulk material and has a high aspect ratio. In a coating, both interfaces must be maintained. If the difference in CTE between deposited and substrate is too high, additional heat treatments can cause further damage. To illustrate this, the stress from a temperature change applied to all coatings on SiC is shown in Figure 13.

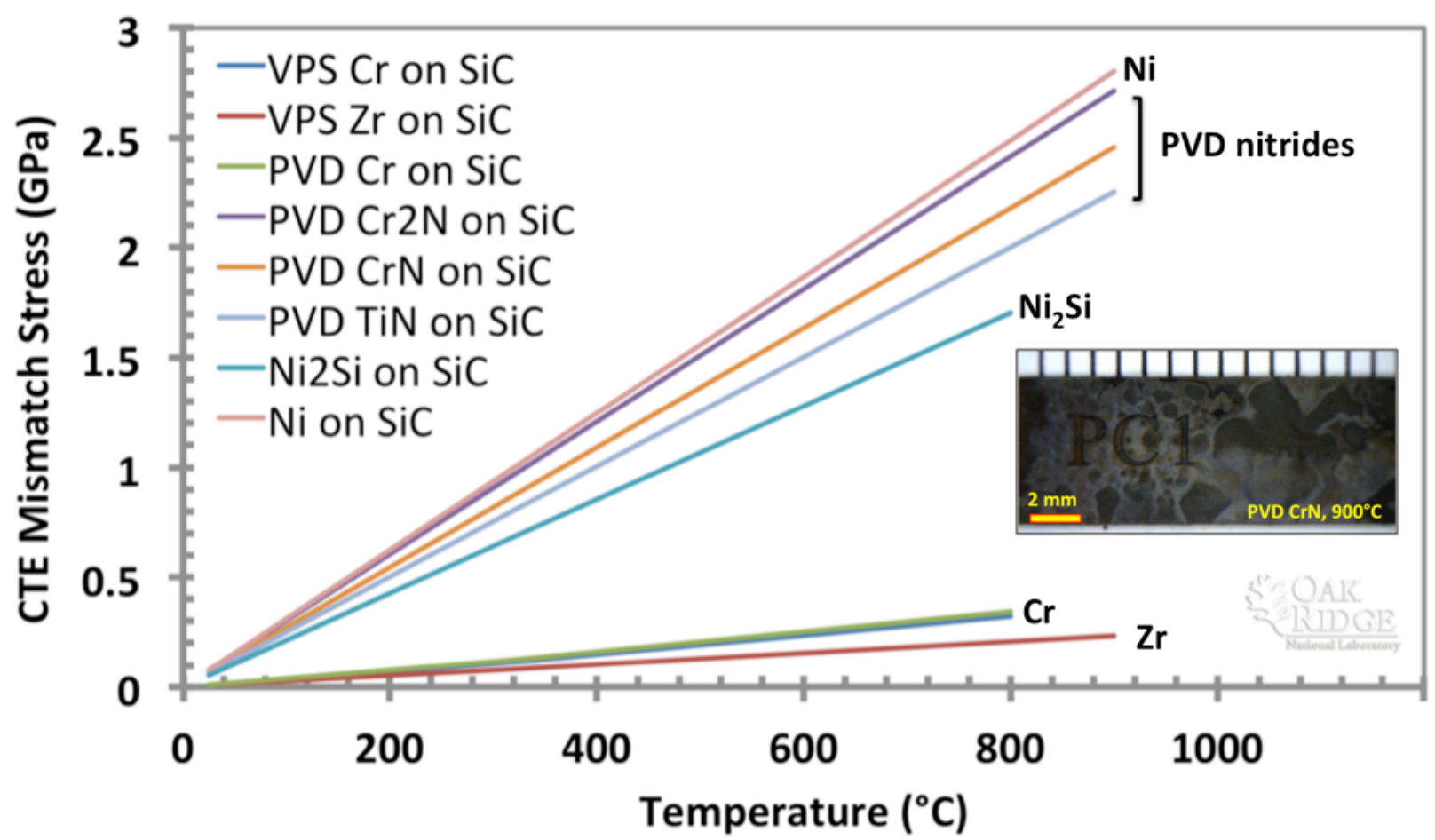

Figure 13. Magnitude of CTE mismatch stresses based on deposition coatings of electrochemical, PVD and VPS coatings and material-types. Inset shows typical morphology of high CTE coating on low CTE SiC after elevated temperature.

The temperature range includes $320^{\circ} \mathrm{C}$ (LWR) up to $900^{\circ} \mathrm{C}$, as it is the approximate range where the diffusivity of metals into $\mathrm{SiC}$ initiates early reduction reactions). This uses a thin film calculation, which is an approximation that uses room temperature CTE, and does not include stress dissipation of the system that will vary between fcc, bcc and hcp-type materials with temperature.[28, 33, 49] Figure 13 provides a good 
comparison of the magnitude of the problem if a temperature is imposed on the interface. Note the coating stress is compressive during heating because all the coatings expand and contract at a higher rate than SiC. The stress in $\mathrm{SiC}$ is tensile, as it attempts to maintain the interface with a rapidly expanding metal.

In some cases, the CTE mismatch stress for the coating-substrate system at PWR operational regimes approaches $\sim 1 \mathrm{GPa}$. For heat treatment at $\sim 800-900^{\circ} \mathrm{C}$, the value significantly exceeds $2 \mathrm{GPa}$. This clearly shows the non-trival level of stresses that must be accounted for. The inset in Figure 13 shows a typical result of heat treatment of a high CTE coating on a low CTE substrate like SiC. A blistering morphology was observed, and consistent in most cases where compressive stress exceeded $\sim 1 \mathrm{GPa}$ during heat treatment. Figure 13 that heat treatment is more likely to benefit constrained systems that have small CTE difference to $\mathrm{SiC}$ or can mitigate the stress in their microstructure.

The second aspect to consider is the coating microstructure after processing, which is a function of variables such as the type of crystal structure and the way it responds to stresses. Using Figure 13, it appears that $\mathrm{Cr}$ and $\mathrm{Zr}$ would have smaller CTE mismatch. Figure 14 shows the results of a heat treatment of $\mathrm{Cr}$ and $\mathrm{SiC}$.

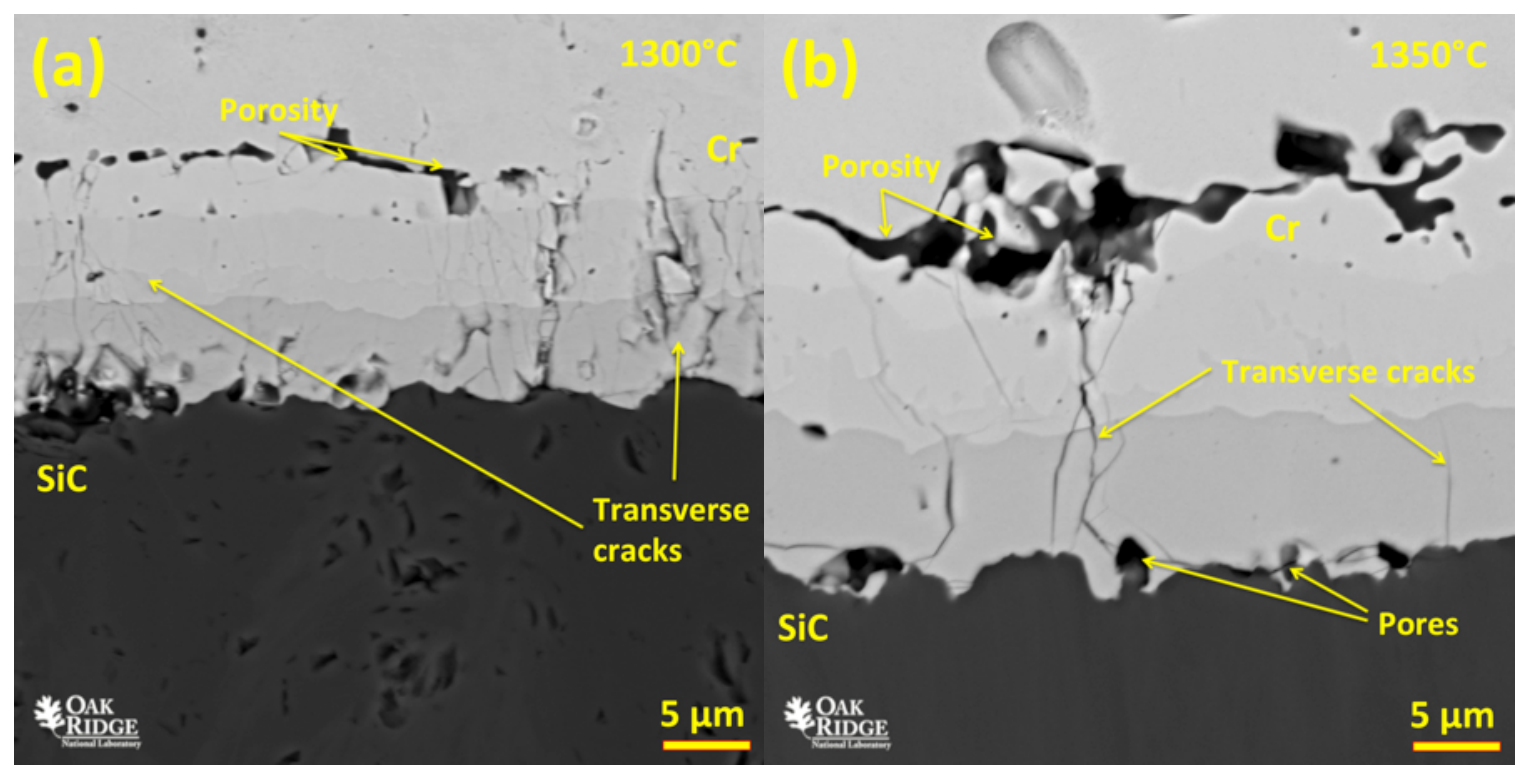

Figure 14. $\mathrm{Cr} / \mathrm{SiC}$ interface after heating to (a) $1300^{\circ} \mathrm{C}$ and (b) $1350^{\circ} \mathrm{C}$. Note the Kirkendall void plane, and transverse cracks despite the close CTE values of SiC and Cr.

A number of interphases were formed between the two phases. As the temperature increased, the size of the interphases became larger. Chromium cannot diffuse into the $\mathrm{SiC}$ lattice without reaction, and these phases were likely based on $\mathrm{Cr}_{x} \mathrm{Si}_{\mathrm{y}}$ stoichiometry, and secondary interphases that react with liberated $\mathrm{C}$ to form $\mathrm{Cr}_{x} \mathrm{Si}_{y} \mathrm{C} .[48,50]$ This improves adhesion strength between the layers.

Regardless of strength of this diffusion bond, this morphology could be considered unsuitable because flaws have been produced. Transverse cracking normal to the interface direction is often indicative of CTE mismatch. However, while the mismatch stresses are relatively low, Cr metal or new interphases may not have the ability to dissipate stresses due to their crystal structure. Secondly, it appeared that a Kirkendall void plane formed in the upper $\mathrm{Cr}$ layer. This is a typical phenomenon occurring in diffusional processes when one species (Cr) diffuses quicker than the other.[48, 50] The void layer is observed by the denoted longitudinal porosity in Figure 14. 
In summary, heat treatments are an option to increase the strength between coating and substrate, but the magnitude of CTE mismatch, stress dissipation mechanisms, and resulting morphologies must be considered.

\subsubsection{Fuel assembly depletion simulations}

In considering the practical application of the metallic-based coating in electrochemical deposition methods, it is of interest to estimate the penalty to the cycle length of a typical LWR core when the proposed coating is introduced.

To this end, Table IV gives the single-batch discharge burnup interpolated from the reactivity trend as well as the 3-batch cycle length in effective full power days (EFPD) computed with the linear reactivity model for each case. The impact of application of the nickel coating is readily apparent; nontrivial losses in cycle length due to the coating are seen in comparing cases 2 and 3, cases 4 and 5, and cases 6 and 7. The average loss in cycle length due to application of $40 \mu \mathrm{m}$ of coating is $37 \mathrm{EFPD}$; application of $20 \mu \mathrm{m}$ of coating yielded a cycle penalty of 24 EFPD. The average gain in cycle due to enrichment is 107 EFPD/\%. Additionally, a gain of 12 EFPD was achieved in replacing the Zr-based clad with SiC.

Table IV. Discharge Burnup

\begin{tabular}{|l|l|l|}
\hline Case & Single-Batch Discharge Burnup (GWd/MT) & 3-Batch Cycle Length (EFPD) \\
\hline 1 & 30.78 & 385 \\
\hline 2 & 31.76 & 397 \\
\hline 3 & 29.85 & 373 \\
\hline 4 & 22.92 & 287 \\
\hline 5 & 20.01 & 250 \\
\hline 6 & 40.09 & 501 \\
\hline 7 & 37.09 & 464 \\
\hline
\end{tabular}

Least squares regression is now applied to parameterize the computed 3-batch cycle length in terms of enrichment and coating thickness using only the data from the cases with SiC cladding (cases 2-6). End-ofcycle burnup, and therefore also cycle length, is assumed to be linear with respect to enrichment as well as the volume of coating material present. The parameterization therefore takes the following form:

$$
\widehat{T}=a_{0}+a_{1} e+a_{2} t_{N i}+a_{3} t_{N i}^{2}+a_{4} t_{C r}+a_{5} t_{C r}^{2}
$$

where $\mathrm{T}$ is the 3-batch cycle length (and the hat notation indicates the regression estimate), e is enrichment in percent, $\mathrm{t}$ is the coating thickness in $\mu \mathrm{m}$, and the $\mathrm{a}_{\mathrm{i}}$ 's are the parameters. Carrying out the standard regression analysis [8] yields the following parameter values:

$$
\begin{gathered}
a_{0}=-33 \\
a_{1}=107 \\
a_{2}=-4.96 \times 10^{-4} \\
a_{3}=-0.0133 \\
a_{4}=-6.16 \times 10^{-4} \\
a_{5}=-0.0185
\end{gathered}
$$


The increase in enrichment required to offset the introduction of a given coating thickness can be found by setting $e \rightarrow e+\delta_{e}$ and forcing the $\delta_{\mathrm{e}}$ term to balance the coating thickness terms in Equation 1a. Rearranging the terms yields:

$$
\delta_{e}=4.64 \times 10^{-6} t_{N i}+1.24 \times 10^{-4} t_{N i}^{2}+5.76 \times 10^{-6} t_{C r}+1.73 \times 10^{-4} t_{C r}^{2}
$$

The least squares model indicates that both the nickel and the chromium layers have a significant impact on the achievable cycle length; in fact, the dependence on the chromium thickness is stronger than that of the nickel thickness. Figure 15 separately plots the contributions to additional required enrichment of the nickel and chromium over the range $0-40 \mu \mathrm{m}$.

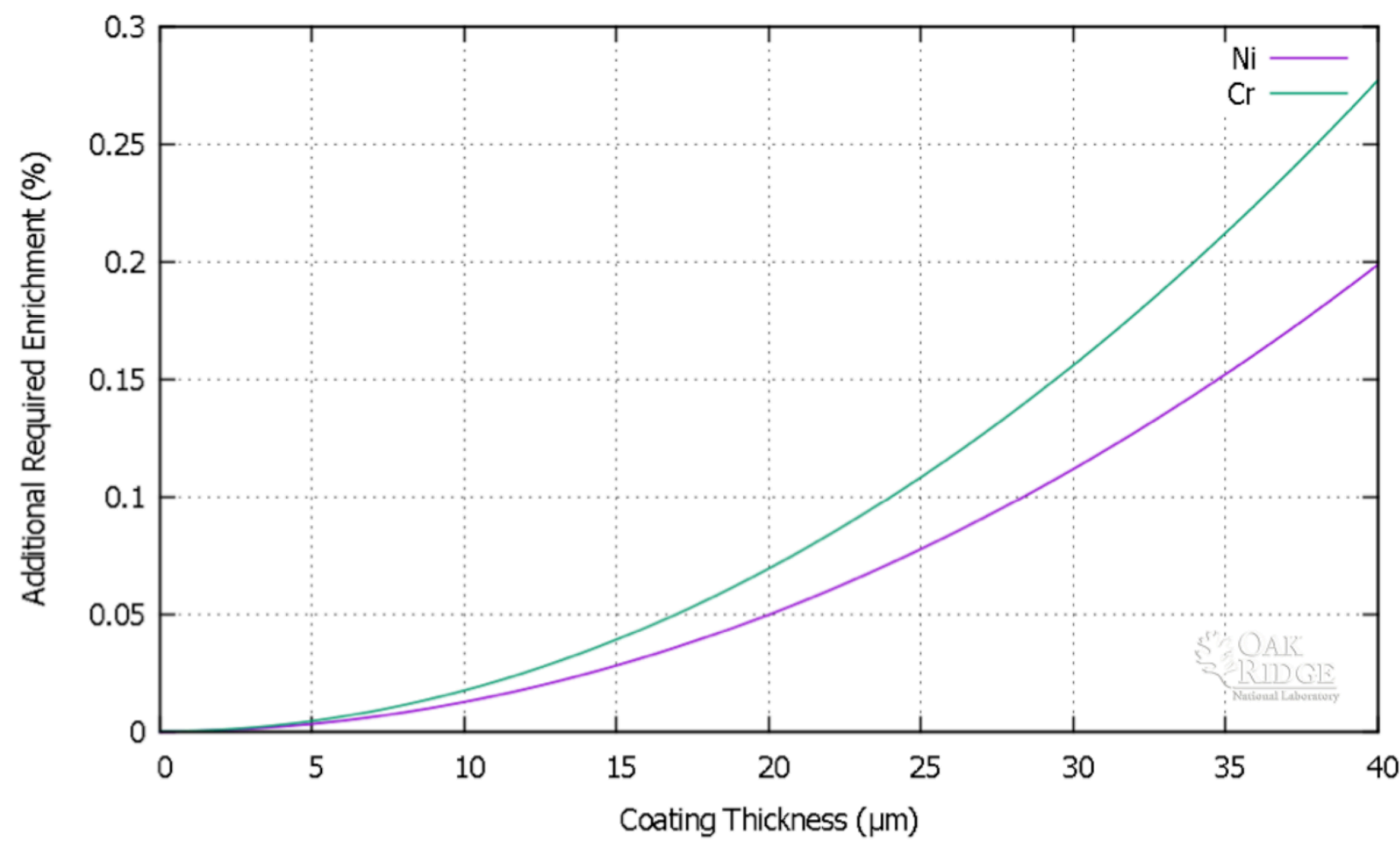

Figure 15. Additional enrichment required, based on varying $\mathrm{Ni}$ and $\mathrm{Cr}$ thickness using current modelling.

The total additional enrichment required is the sum of the individual contributions of the nickel and chromium layers defined by the curves in Figure 15; for example, for $15 \mu \mathrm{m}$ of nickel and $15 \mu \mathrm{m}$ of chromium, the additional enrichment necessary to maintain cycle length is approximately $0.03 \%+0.04 \%=0.07 \%$.

As noted, chromium is the coolant facing material, and electrochemical deposition cannot easily mitigate tensile stresses. The current variable of interest is whether it is possible to mitigate the tensile stress using the nickel bond coat. This addresses the feasibility of electrolytic chromium using a nickel bond coat. For example, assuming the chromium layer must be present with a constant thickness of $30 \mu \mathrm{m}$ (for microcrack mitigation) for any nickel coating thickness, Equation 2 simplifies to:

$$
\delta_{e}=0.156+4.64 \times 10^{-6} t_{N i}+1.24 \times 10^{-4} t_{N i}^{2}
$$


Again, the enrichment must be expressed in percent and the coating thickness in $\mu \mathrm{m}$. This relation is plotted over the range of coating thickness $0-40 \mu \mathrm{m}$ in Figure 16. The effect of the fixed $30 \mu \mathrm{m}$ layer of chromium is an immediate requirement of $0.156 \%$ additional enrichment to offset its reactivity penalty. The additional enrichment necessitated by the nickel is nontrivial but modest; for the maximum of $40 \mu \mathrm{m}$ of nickel, the total additional enrichment required to maintain cycle length is about $0.356 \%$. In practice, the nickel layer will likely be applied in quantities smaller than this $40 \mu \mathrm{m}$, yielding limited increases in the required enrichment.

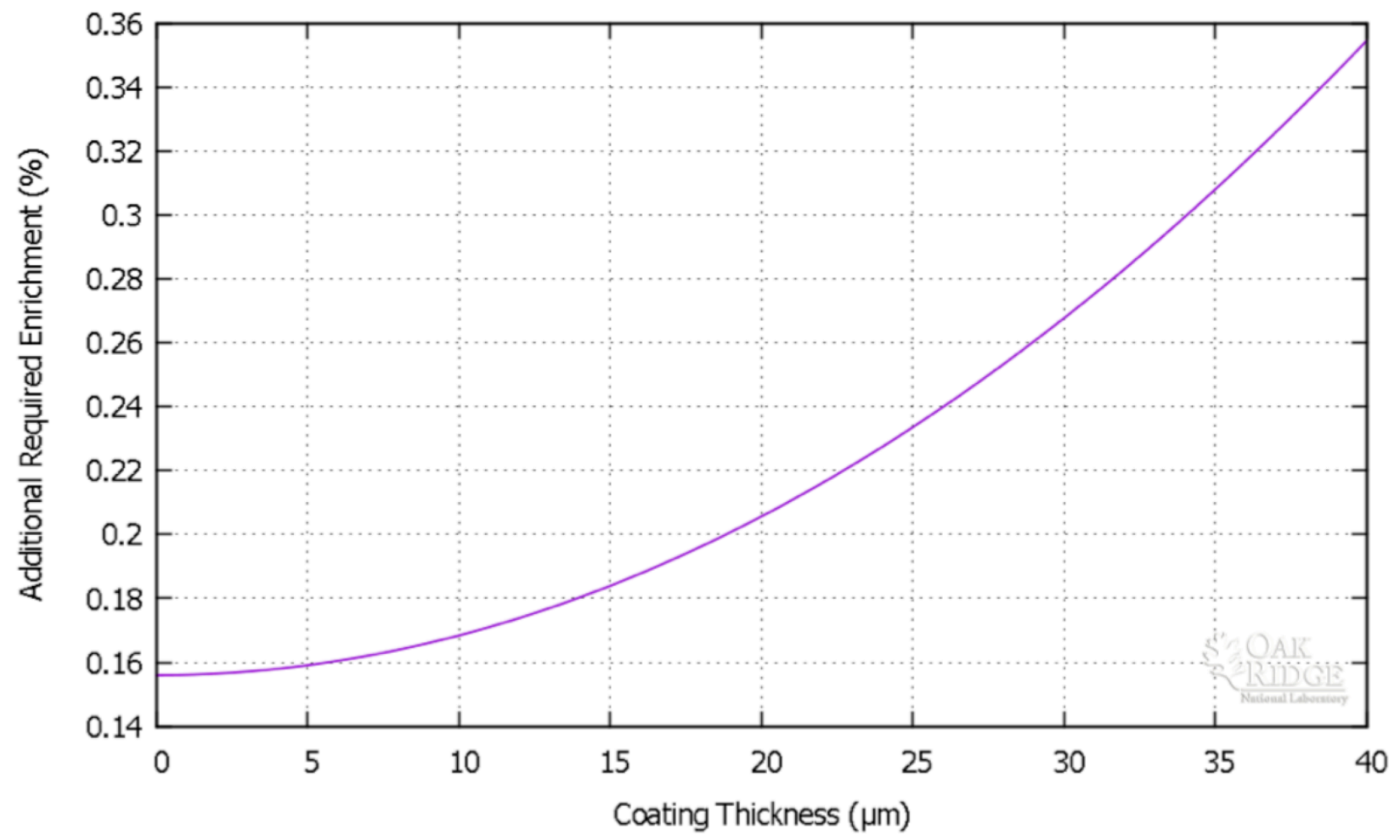

Figure 16. Increase in Enrichment Required to Offset Nickel-bond coat when chromium is fixed at $\sim 30 \mu \mathrm{m}$ thickness.

This depletion analysis provides a rough estimate of the change in fuel assembly enrichment necessary to offset application of a coating with known thickness. It is found that the chromium layer has a greater impact on the achievable cycle length than the nickel layer; thus, savings in enrichment can be realized if the chromium thickness can be safely reduced. The reactivity contribution of the nickel is modest throughout the thickness range studied here; therefore, the additional enrichment requirements are likely manageable if the coating application can be limited to moderate thickness. This satisfies one of the important criteria of a "drop-in replacement" approach to ATF.[51]

Unfortunately, reduction in thickness requires significant improvement in coating processing and morphology. Since $\mathrm{Ni}$ is one of the bond coats to mitigate tensile stresses of electrolytic chromium, the focus on "softer" chrome alloys, or the development of SiC-PyC graded interfaces is the logical next step. A success in $\mathrm{SiC}-\mathrm{PyC}$ graded interface production, as noted in Figure 8, can also be plated directly by $\mathrm{Cr}$ without the presence of $\mathrm{Ni}$ as a bond coat. 


\subsection{FUTURE WORK}

Several coatings have been developed and are currently undergoing development and down-selection. All coatings are currently undergoing in-pile irradiations followed by mechanical testing and cross-section microscopy. Coolant exposure in autoclaves are underway. Processing is being conducted in consideration of neutron economy, with further modeling underway. The current directions for each technology are as follows:

- Electrolytic chromium or "hard chrome" required advanced surface preparation as it cannot easily mitigate the tensile stress; a change substrate morphology through a graded SiC-PyC interface may be effective in improving adhesion strength. Pursuit of a suitable collaboration with an industry partner continues, but the development of new types of CVI/CVD SiC and PyC appears limited. As a contingency, alloying of the chromium is being pursued, targeting a lower modulus for reduced microcracking.

- PVD has no technological hurdles remaining, and appears most promising. The tensile stresses are mitigated by ion peening, and defense in depth is provided by multilayers. The use of PVD Cr (as a substitute for other technologies to subsequently surpass) is currently underway as it is the only ready candidate. The nitrides are currently being assessed for radiation tolerance. However, scaling of this technology is less economical.

- VPS currently faces processing challenges with $\mathrm{Zr}$ due to surface reactions with SiC. The annealing of the tensile stresses and likely high bonding strength are main advantages of this coating. The use of Zircaloy-2 gives VPS an advantage for long-term implementation, but the scaling of VPS technology, process control and texture may be a significant challenge. Attempts using VPS Cr powder are scheduled for late-2016. 


\section{CONCLUSIONS}

The modification of $\mathrm{SiC}_{\mathrm{f}} \mathrm{SiC}$ composites for resistance to microcracking and hydrothermal corrosion is necessary for its deployment as Light Water Reactor (LWR) fuel cladding. To this end, Oak Ridge National Laboratory is exploring coating technologies as a solution to both problems. SiC coupons were prepared for coating by industrially-available technologies. Electrolytic chromium, Physical Vapor Deposition (PVD) and Vacuum Plasma Spray (VPS) were investigated for the ability to deposit coatings on SiC. All three technologies required significant process innovations to reach demonstration capability. From X-ray Diffraction, stress analysis, and microstructure, the following key features have been identified. VPS coatings are at least $\sim 50$ $\mu \mathrm{m}$ in thickness, while hard chrome must be at least $\sim 30 \mu \mathrm{m}$ thick. PVD thicknesses vary from 2-20 $\mu \mathrm{m}$. The coatings experienced tensile stresses from constraint to a ceramic substrate, except in PVD. In electrolytic chromium, stress was alleviated by microcracking. In VPS and PVD, stresses were mitigated without obvious damage. Under SEM examination, VPS and electrolytic systems have high diffusivity microcracks and pores that would make them unsuitable for hermeticity or corrosion resistance. Coatings of $\mathrm{Ni}$ and $\mathrm{Cr}$ must be limited to $<30 \mu \mathrm{m}$ thickness based neutron depletion analysis. The preliminary examination and phase analysis indicated that two coating technologies (VPS and electrolytic) require optimizations, and only PVD was suitable for early evaluations. Both vacuum and vapor-technologies cannot be easily scaled and a fullydeveloped electrolytic method is the most appealing long-term solution.

\section{ACKNOWLEDGEMENTS}

The authors would like to thank Shawn Reeves, Stephanie Curlin, Jordan Couch and Jim Kiggans for technical support, and Takaaki Koyanagi for technical review of this manuscript. The authors gratefully thank Aaron Selby, Brian Jolly, Caleb Massey and Craig Kemery (NEO Knoxville, LLC) for specimen preparation. Research was conducted at the High Temperature Materials Laboratory (HTML). Research sponsored by the Advanced

Fuels Campaign of the Fuel Cycle R\&D program, Office of Nuclear Energy, US Department of Energy, under contract DE-AC05-000R22725 with UT-Battelle, LLC. 


\section{REFERENCES}

[1] K. Yueh, K.A. Terrani, J. Nucl. Mater., 448 (2014) 380-388.

[2] K.A. Terrani, L.L. Snead, J.C. Gehin, J. Nucl. Mater., 427 (2012) 209-224.

[3] K.A. Terrani, Y. Yang, Y.J. Kim, R. Rebak, H.M. Meyer Iii, T.J. Gerczak, J. Nucl. Mater., 465 (2015) 488-498.

[4] E. Barringer, Z. Faiztompkins, H. Feinroth, T. Allen, M. Lance, H. Meyer, L. Walker, E. Lara-Curzio, J. Am. Ceram. Soc., 90 (2007) 315-318.

[5] W.-J. Kim, H.S. Hwang, J.Y. Park, W.-S. Ryu, J. Mater. Sci. Lett., 22 (2003) 581-584.

[6] H. Hirayama, T. Kawakubo, A. Goto, T. Kaneko, J. Am. Ceram. Soc., 72 (1989) 2049-2053.

[7] D.M. Carpenter, Massachusetts Institute of Technology, 2010.

[8] H.E. Khalifa, C.P. Deck, O. Gutierrez, G.M. Jacobsen, C.A. Back, J. Nucl. Mater., 457 (2015) $227-$ 240.

[9] J.G. Stone, R. Schleicher, C.P. Deck, G.M. Jacobsen, H.E. Khalifa, C.A. Back, J. Nucl. Mater., 466 (2015) 682-697.

[10] C.P. Deck, G.M. Jacobsen, J. Sheeder, O. Gutierrez, J. Zhang, J. Stone, H.E. Khalifa, C.A. Back, J. Nucl. Mater., 466 (2015) 667-681.

[11] R.J. Price, Journal of Nuclear Materials, 33 (1969) 17.

[12] L.L. Snead, T. Nozawa, Y. Katoh, T.S. Byun, S. Kondo, D.A. Petti, Journal of Nuclear Materials, 371 (2007) 329-377.

[13] T. Cheng, J.R. Keiser, M.P. Brady, K.A. Terrani, B.A. Pint, J. Nucl. Mater., 427 (2012) 396-400.

[14] S. Lawson, J. Eur. Ceram. Soc., 15 (1995) 485-502.

[15] P. Sahoo, S.K. Das, Mater. Des., 32 (2011) 1760-1775.

[16] J. Sudagar, J. Lian, W. Sha, J. Alloys Compd., 571 (2013) 183-204.

[17] S. Kundu, S.K. Das, P. Sahoo, Procedia Engineering, 97 (2014) 1698-1706.

[18] G.O. Mallory, J.B. Hajdu, Electroless plating: fundamentals and applications, in, William Andrew, 1990, pp. 57-98.

[19] L.L. Snead, M.C. Osborne, R.A. Lowden, J. Strizak, R.J. Shinavski, K.L. More, W.S. Eatherly, J. Bailey, A.M. Williams, J. Nucl. Mater., 253 (1998) 20-30.

[20] S. O'Dell, L.L. Snead, 40th International Conference and Exposition on Advanced Ceramics and Composites, January 24-29, (2016).

[21] K.E. Rea, V. Viswanathan, A. Kruize, J.T.M. De Hosson, S. O'Dell, T. McKechnie, S. Rajagopalan, R. Vaidyanathan, S. Seal, Materials Science and Engineering: A, 477 (2008) 350-357.

[22] N.M. George, K. Terrani, J. Powers, A. Worrall, I. Maldonado, Annals of Nuclear Energy, 75 (2015) 703-712.

[23] N.R. Brown, A. Aronson, M. Todosow, R. Brito, K.J. McClellan, Nucl. Eng. Des., 275 (2014) 393407.

[24] N.R. Brown, M. Todosow, A. Cuadra, J. Nucl. Mater., 462 (2015) 26-42.

$[25]$

[26] N.M. Martyak, J.E. McCaskie, B. Voos, W. Plieth, J. Mater. Sci., 32 (1997) 6069-6073.

[27] G. Janssen, F. Tichelaar, C. Visser, J. Appl. Phys., 100 (2006) 093512.

[28] F.A. Doljack, R.W. Hoffman, Thin Solid Films, 12 (1972) 71-74.

[29] E. Bromley, J. Randall, D. Flanders, R. Mountain, Journal of Vacuum Science \& Technology B, 1 (1983) 1364-1366.

[30] R.C. Cammarata, J.C. Bilello, A.L. Greer, K. Sieradzki, S.M. Yalisove, MRS Bull., 24 (1999) 34-38.

[31] F. Spaepen, Acta Mater., 48 (2000) 31-42.

[32] G.C.A.M. Janssen, A.J. Dammers, V.G.M. Sivel, W.R. Wang, Appl. Phys. Lett., 83 (2003) 3287-

3289.

[33] N. Schwarzer, F. Richter, (2006).

[34] G.C.A.M. Janssen, Thin Solid Films, 515 (2007) 6654-6664. 
[35] J. Torres-Gonzalez, F. Castaneda, P. Benaben, Leonardo Electronic Journal of Practices and Technologies, (2010) 117-130.

[36] C. Ang, Y. Katoh, C. Kemery, J. Kiggans, K. Terrani, Transactions of the American Nuclear Society, Summer Meeting, New Orleans, 114 (2016).

[37] Y. Matsumoto, M. Morinagat, M. Furui, Scr. Mater., 38 (1997) 321-327.

[38] R. Hoy, W. Sloof, G. Janssen, Surf. Coat. Technol., 179 (2004) 215-222.

[39] R. Hoy, V. Sivel, J.-D. Kamminga, G. Janssen, Surf. Coat. Technol., 200 (2005) 149-152.

[40] R. Hoy, J.-D. Kamminga, G. Janssen, Surf. Coat. Technol., 200 (2006) 3856-3860.

[41] J.J. Olaya, G. Wei, S.E. Rodil, S. Muhl, B. Bhushan, Vacuum, 81 (2007) 610-618.

[42] S.-Y. Chun, Journal of the Korean Physical Society, 56 (2010) 1134-1139.

[43] J. Lin, W.D. Sproul, J.J. Moore, S. Lee, S. Myers, Surf. Coat. Technol., 205 (2011) 3226-3234.

[44] X. Guan, Y. Wang, Q. Xue, L. Wang, Surf. Coat. Technol., 282 (2015) 78-85.

[45] L. Shan, Y.-X. Wang, J.-1. Li, H. Li, X. Lu, J.-m. Chen, Transactions of Nonferrous Metals Society of China, 25 (2015) 1135-1143.

[46] Y. Liu, I. Bhamji, P.J. Withers, D.E. Wolfe, A.T. Motta, M. Preuss, J. Nucl. Mater., 466 (2015) 718 727.

[47] K. Daub, R. Van Nieuwenhove, H. Nordin, J. Nucl. Mater., 467, Part 1 (2015) 260-270.

[48] J.H. Gülpen, A.A. Kodentsov, F.J.J.v. Loo, Mater. Sci. Forum, 155-156 (1994) 561-564.

[49] M. Ohring, Materials science of thin films. 2nd ed, Academic Press, Boston, 1992, 2010.

[50] F. Jicai, L. Huijie, M. Naka, J.C. Schuster, J. Mater. Sci. Lett., 20 (2001) 301-302.

[51] S.J. Zinkle, K.A. Terrani, J.C. Gehin, L.J. Ott, L.L. Snead, J. Nucl. Mater., 448 (2014) 374-379. 